Article

\title{
Evaluation of Simplified Polarimetric Decomposition for Soil Moisture Retrieval over Vegetated Agricultural Fields
}

\author{
Hongquan Wang ${ }^{1, *}$, Ramata Magagi ${ }^{1}$, Kalifa Goita ${ }^{1}$, Thomas Jagdhuber ${ }^{2}$ and Irena Hajnsek ${ }^{2,3}$ \\ 1 Centre d'applications et de Recherches en Télédétection (CARTEL), Université de Sherbrooke, Sherbrooke, \\ QC J1K2R1, Canada; Ramata.Magagi@USherbrooke.ca (R.M.); Kalifa.Goita@USherbrooke.ca (K.G.) \\ 2 Microwaves and Radar Institute, German Aerospace Center, Oberpfaffenhofen 82234, Germany; \\ Thomas.Jagdhuber@dlr.de (T.J.); irena.hajnsek@dlr.de (I.H.) \\ 3 Institute of Environmental Engineering, Swiss Federal Institute of Technology Zurich, \\ Zurich 8093, Switzerland \\ * Correspondence: Hongquan.Wang@USherbrooke.ca; Tel.: +1-819-821-8000 (ext. 62956)
}

Academic Editors: Nicolas Baghdadi and Prasad S. Thenkabail

Received: 17 December 2015; Accepted: 4 February 2016; Published: 10 February 2016

\begin{abstract}
This paper investigates a simplified polarimetric decomposition for soil moisture retrieval over agricultural fields. In order to overcome the coherent superposition of the backscattering contributions from vegetation and underlying soils, a simplification of an existing polarimetric decomposition is proposed in this study. It aims to retrieve the soil moisture by using only the surface scattering component, once the volume scattering contribution is removed. Evaluation of the proposed simplified algorithm is performed using extensive ground measurements of soil and vegetation characteristics and the time series of UAVSAR (Uninhabited Aerial Vehicle Synthetic Aperture Radar) data collected in the framework of SMAP (Soil Moisture Active Passive) Validation Experiment 2012 (SMAPVEX12). The retrieval process is tested and analyzed in detail for a variety of crops during the phenological stages considered in this study. The results show that the performance of soil moisture retrieval depends on both the crop types and the crop phenological stage. Soybean and pasture fields present the higher inversion rate during the considered phenological stage, while over canola and wheat fields, the soil moisture can be retrieved only partially during the crop developing stage. RMSE of $0.06-0.12 \mathrm{~m}^{3} / \mathrm{m}^{3}$ and an inversion rate of $26 \%-38 \%$ are obtained for the soil moisture retrieval based on the simplified polarimetric decomposition.
\end{abstract}

Keywords: soil moisture; vegetation; agricultural fields; polarimetric decomposition; SMAPVEX12; UAVSAR

\section{Introduction}

For agricultural fields, soil moisture is an important factor for several physical processes such as water conservation, soil erosion and surface runoff. In contrast to the conventional soil moisture acquisitions consisting of point samplings which are time and labor consuming, Synthetic Aperture Radar (SAR) presents the potentials to extract (sub-) surface information with high spatial and temporal resolution. Furthermore, polarimetric SAR extends the observation space, providing more promising approaches for the retrieval of the soil parameters under different crop conditions, types and phenological stages [1,2]. Nevertheless, over agricultural vegetated fields, the effects of vegetation layers (mainly described by shape, structure, orientation and phenological developing stage) and the underlying soils (mainly described by soil moisture and surface roughness) are coherently 
superimposed in the measured SAR signature [1-4]. As a consequence, the soil moisture retrieval over vegetated agricultural soils is a challenge addressed by several authors in the past decades [1-9]. On one hand, the vegetation layer is modeled and removed using incoherent radiative transfer approach [6]. Such a model considers the total backscattering coefficient as an incoherent sum of the scattering contributions from the vegetation volume scattering, the soil scattering and their interaction. For instance, the well-known water-cloud model [7], which is widely used for soil moisture retrieval, is a simple first-order radiative transfer solution which neglects the multiple scattering, and assumes that the vegetation and the underlying soil contributions are incoherently added up. On the other hand, based on the polarimetric SAR measurements, the target decomposition methodologies [10-12] are used to remove the vegetation component and estimate the underlying soil moisture from the ground scattering component. For example, the three-component model-based polarimetric decomposition [10] has been adapted [1-3] for soil moisture estimation under vegetation. In addition to the aforementioned soil moisture retrieval methods from radiative transfer models and polarimetric decomposition, empirical relationships [5,13-17] were also developed between polarimetric SAR-derived parameters, vegetation and/or soil variables in order to improve the soil moisture retrieval in an easier way.

Considering the known sensitivity of SAR signature to soil and vegetation parameters, the SMAP (Soil Moisture Active Passive) Validation Experiment in 2012 (SMAPVEX12) was established for a launch assessment of SMAP products $[18,19]$. Within the framework of SMAPVEX12, both airborne radar data and expansive ground measurements of soil and vegetation characteristics were collected in order to evaluate, enhance and develop soil moisture retrieval algorithms.

In this paper, we will take advantage of the polarimetric Uninhabited Aerial Vehicle Synthetic Aperture Radar (UAVSAR) data of SMAPVEX12 collected during most part of crop growth season to evaluate an existing polarimetric decomposition soil moisture retrieval algorithm [1]. Indeed, both the surface and dihedral scattering components are used in [1] to retrieve soil moisture. Nevertheless, low accuracy and retrieval rate were obtained from the dihedral component which is a function of vegetation and soil characteristics. Furthermore, at a $45^{\circ}$ incidence angle, the dihedral component presents an ambiguity to separate the vegetation and soil moistures, hindering the robustness of soil moisture retrieval over vegetated fields. If the dihedral component is included in the retrieval process [1], the overall accuracy decreased. Thus, this paper proposes a simplification of [1] for soil moisture retrieval at L-band by using only the surface scattering component. This simplified algorithm for soil moisture retrieval is evaluated over a variety of crops, from the early development to the mature stage with maximum height (and biomass). The extensive field data and UAVSAR time series allow this study to focus on the detailed analysis of the model-based decomposition which is conceptually proposed and briefly analyzed in [1]. For instance, in addition to the contribution of vegetation biomass and height, the effect of vegetation water content is analyzed on both the decomposed volume and surface scatterings. Thus, with the detailed data of SMAPVEX12, a thorough reasoning can be conducted in this study, and it can justify the inferences in [1] to confirm eventually the potential of model-based decomposition for soil moisture estimation under vegetation. In this paper, Section 2 describes the datasets acquired in the SMAPVEX12 campaign. Then, the retrieval method is proposed in Section 3. The main results are analyzed and discussed in Section 4 and the conclusion is presented in Section 5.

\section{Study Site and Dataset Presentation}

\subsection{Study Site}

The study site is that of the SMAPVEX12 experiment $[18,19]$ shown in Figure 1 . Since SMAPVEX12 is already documented, we only focus on information relevant for the understanding of this paper. For more details on the SMAPVEX12 site and dataset acquisition, the reader should refer to [18,19]. 


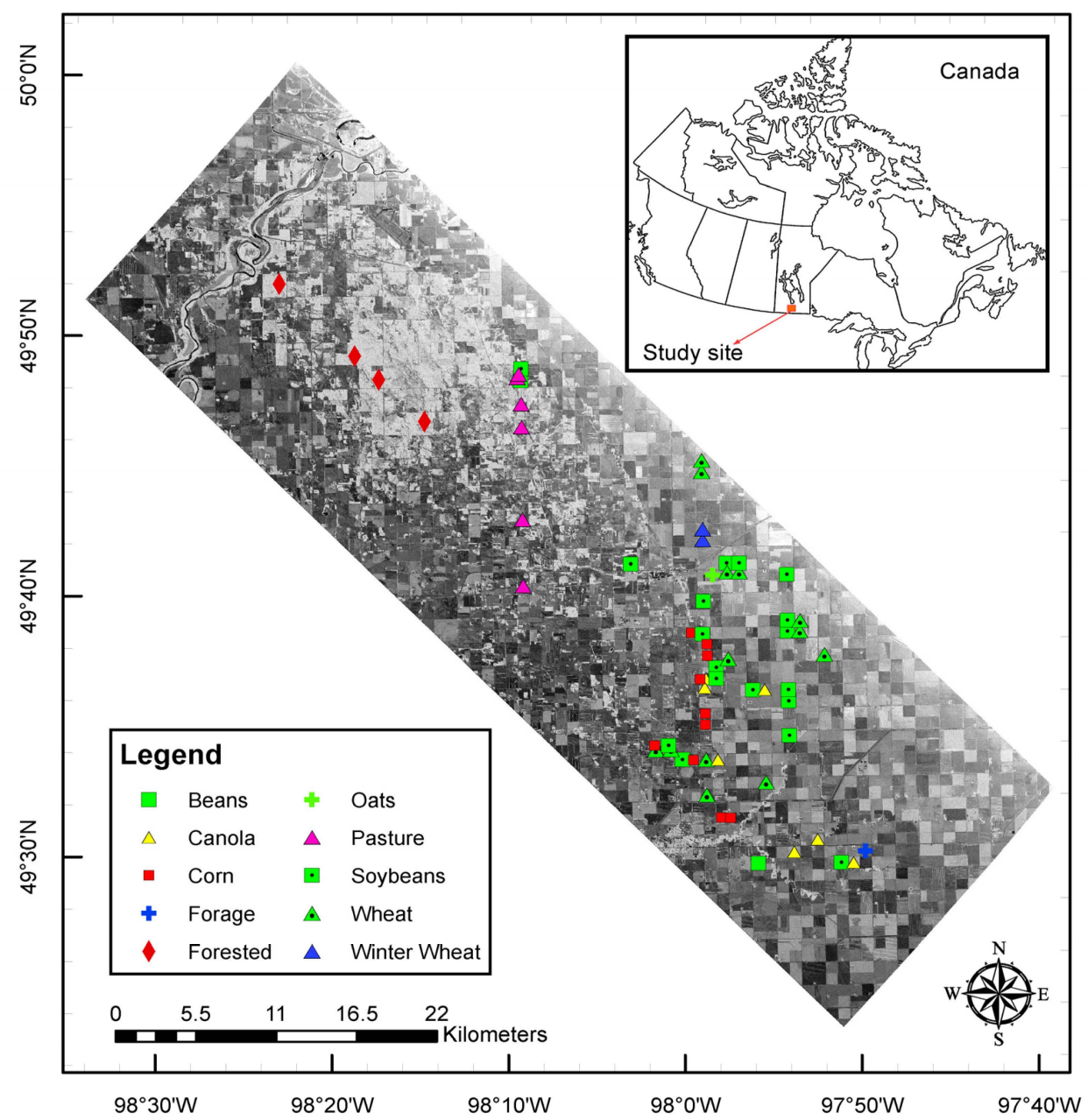

Figure 1. The SMAPVEX12 study site with delineation of UAVSAR swath (gray color image of $\mathrm{T}_{11}$ in $\mathrm{dB}$ ) and corresponding land cover.

The study site covers approximately $15 \mathrm{~km} \times 70 \mathrm{~km}$ and is located within the larger Red River watershed in Manitoba, Canada [18]. It is dominated by several annual crops, including cereals (around $32.2 \%$ of area), canola (13.2\%), corn $(7.0 \%)$ and soybean $(6.7 \%)$. In addition, approximately $16.4 \%$ of the site is occupied by perennial cover (such as grassland and pasture), and some areas are also covered by wetlands and forests [18]. Furthermore, the soil texture varies across the site, thus providing a large range of soil moisture conditions. These diversities in land cover (especially, different crop types) and soil types represent a good opportunity to develop and test the soil moisture retrieval algorithm over vegetation-covered soil.

\subsection{Airborne SAR Data Acquisition and Processing}

During SMAPVEX12, the L-band UAVSAR data were acquired in fine quad-polarization configuration, at $25^{\circ}$ to $65^{\circ}$ incidence angles range, and from 17 June to 17 July 2012. Since the same flight line (\#31606) was used to conduct this study, a given field was observed with the same incidence angle from one acquisition date to another. Table 1 presents the temporal availability of UAVSAR measurements. In this study, the calibrated multi-looked cross products (MLC) with spatial resolution of $5.0 \mathrm{~m}$ in range by $7.2 \mathrm{~m}$ in azimuth are used. The MLC data were firstly extracted as a coherency matrix T3 using PolSARpro4.2 [20]. Then, a boxcar filter with 7-by-7 windows was applied to reduce the speckle effect. As the study area has no topographic variation [19], no compensation of terrain slope was applied on the SAR images. 
Table 1. Julian day (2012) of SAR data acquisition.

\begin{tabular}{cccccccc}
\hline Date & 17 June & 19 June * & 22 June & 23 June & 25 June & 27 June & 29 June \\
\hline Julian (d) & 169 & 171 & 174 & 175 & 177 & 179 & 181 \\
\hline Date & 3 July & 05 July & 08 July & 10 July & 13 July & 14 July & 17 July \\
\hline Julian (d) & 185 & 187 & 190 & 192 & 195 & 196 & 199 \\
\hline \multicolumn{7}{c}{ * no corresponding ground truth measurement (use the field data of 17 June). }
\end{tabular}

\subsection{Ground Measurements}

They consisted of both soil and vegetation characteristics measurements. They were conducted during six weeks from 6 June to 17 July 2012 in order to provide suitable ground measurements for interpreting the collected remote sensing data (including the UAVSAR measurements) with the changes in both soil and vegetation characteristics, developing and testing soil moisture retrieval algorithms under several vegetation types and crop growing stages including the peak season of vegetation cover [18].

(1) Soil Moisture: Almost coincident with each UAVSAR overpass, the volumetric soil moistures of 55 fields were measured at about $6 \mathrm{~cm}$ depth (probe length) using hand-held hydra probes (except for the acquisition on 19 June 2012). Furthermore, the meteorological observations near the test site were simultaneously recorded, providing the experimental conditions for UAVSAR data acquisition and related ground measurements. In Figure 2, the temporal variation of the measured volumetric soil moisture is in agreement with that of the rainfall amount. The peak of the volumetric soil moisture appeared around Julian day 168 as a consequence of successive rain events followed by a significant precipitation of about $30 \mathrm{~mm}$ on Julian 168.

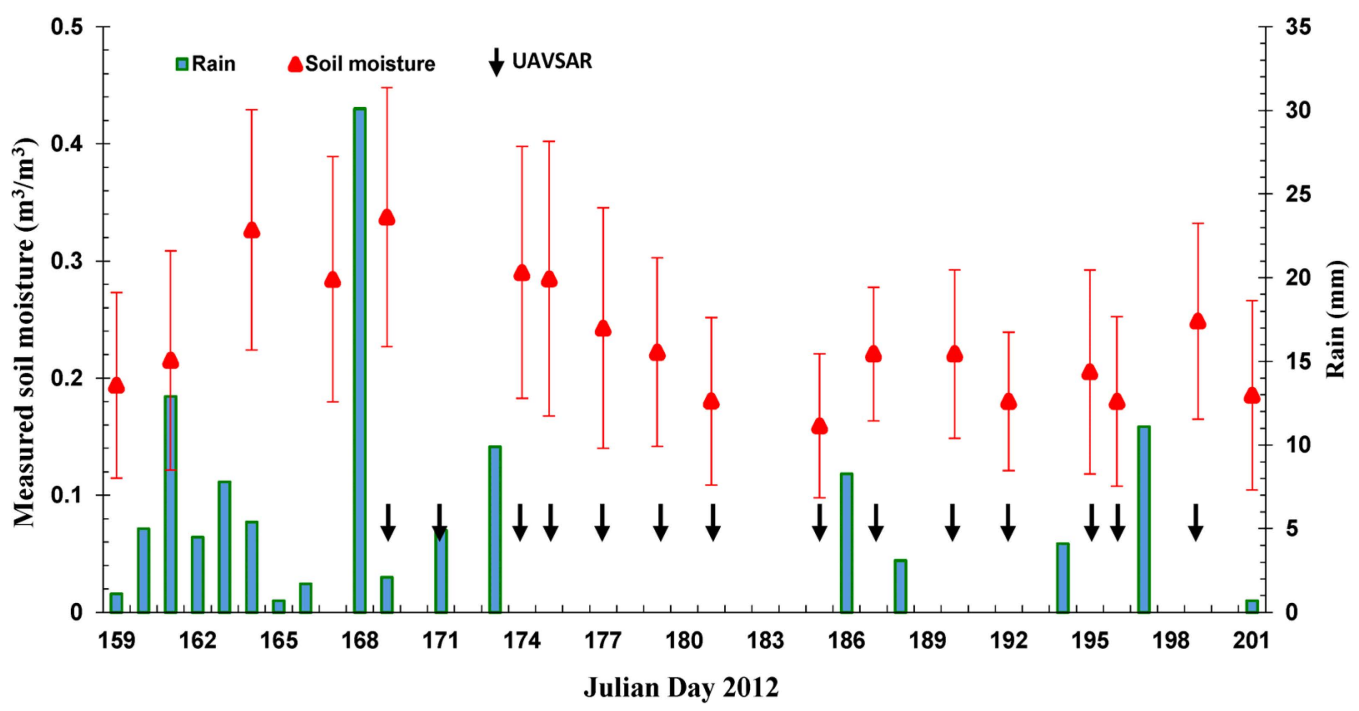

Figure 2. Temporal evolution of the measured volumetric soil moisture along with daily precipitation amount and the availability of UAVSAR acquisitions (black arrows).

(2) Surface Roughness: Soil surface roughness parameters described by the RMS height and the auto correlation length were measured over the 55 fields using a $1 \mathrm{~m}$ long profilometer [18]. Table 2 presents the range of these measurements for canola, corn, pasture, soybean and wheat. The observed field to field variability of roughness parameters results mainly from agricultural practices [19]. The roughness measurements are subsequently used (Section 4.1) to compensate the attenuation of the microwave propagation in order to analyze the scattering mechanisms. 
Table 2. Surface roughness measurements.

\begin{tabular}{ccccccc}
\hline \multirow{2}{*}{ Crops } & \multicolumn{3}{c}{ RMS Height $(\mathbf{c m})$} & \multicolumn{3}{c}{ Correlation Length $(\mathbf{c m})$} \\
\cline { 2 - 7 } & Min & Mean & Max & Min & Mean & Max \\
\hline Canola & 0.75 & 1.22 & 1.59 & 4.50 & 9.25 & 14.25 \\
Corn & 0.80 & 1.21 & 1.79 & 4.00 & 9.75 & 15.50 \\
Pasture & 0.50 & 0.97 & 1.37 & 11.00 & 12.92 & 16.50 \\
Soybean & 0.39 & 0.91 & 1.44 & 5.25 & 11.66 & 17.50 \\
Wheat & 0.68 & 1.12 & 1.88 & 4.00 & 11.75 & 21.25 \\
\hline
\end{tabular}

(3) Vegetation parameters: Measurement of vegetation properties was also an important aspect of the SMAPVEX12 campaign with a main focus on representative crops (canola, corn, soybeans and wheat). The vegetation height and biomass were measured for analyzing the vegetation effects on the L-band microwave signal and subsequently on soil moisture retrieval. Besides, in a post campaign activity, maps of the vegetation water content over the SMAPVEX12 site were derived from SPOT-4 and RapidEye data with an accuracy ranging from $0.13 \mathrm{~kg} / \mathrm{m}^{2}$ to $0.80 \mathrm{~kg} / \mathrm{m}^{2}$ depending on the crop types [21]. For the illustration, Figure 3 shows the measured vegetation height and net wet biomass [18] and the derived vegetation water content [21] of representative crops for the phenological stage considered in this study.

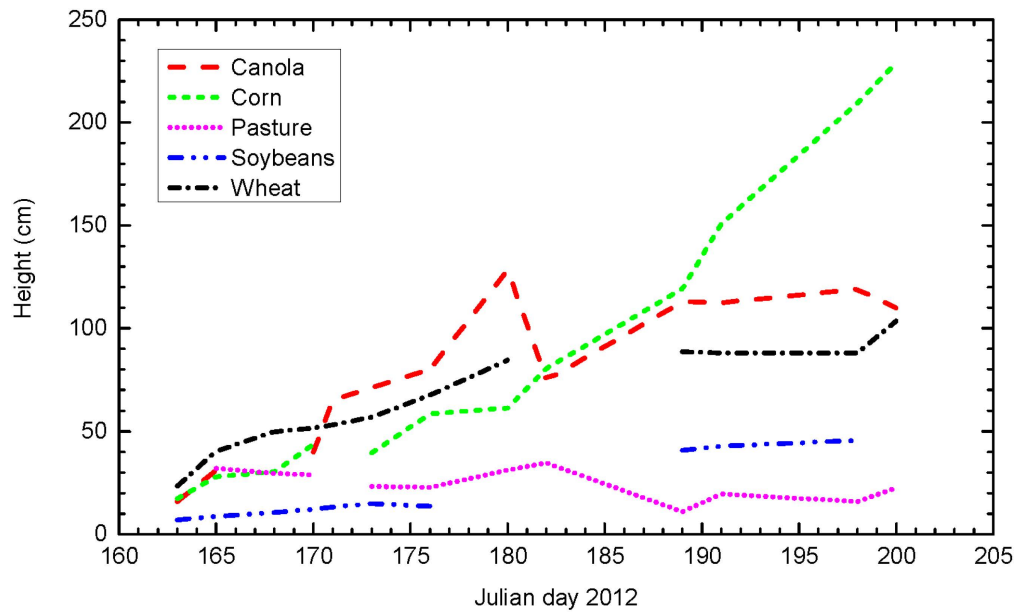

(a)

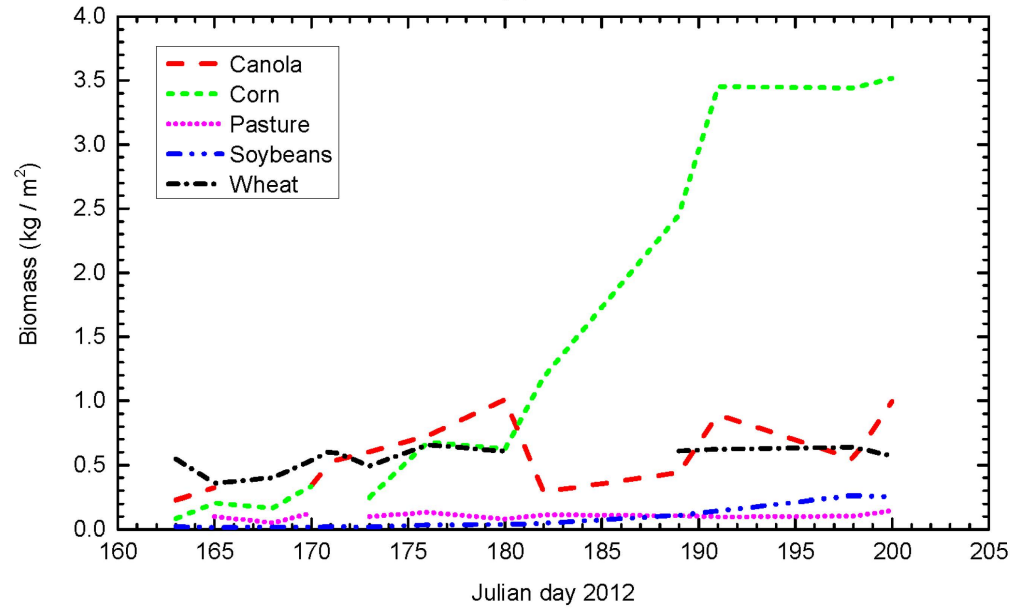

(b)

Figure 3. Cont. 


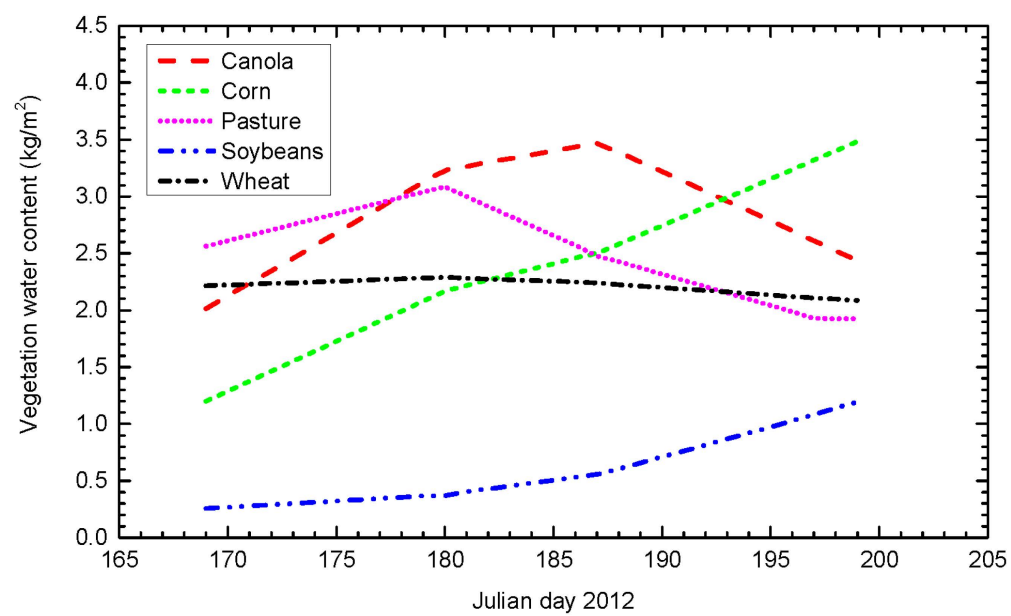

(c)

Figure 3. Temporal variation of vegetation (a) height, (b) wet biomass and (c) vegetation water content.

\section{Method}

Polarimteric decomposition is usually used to deconvolve the different scattering components over a vegetation-covered soil. For soil moisture retrieval using SMAPVEX12 datasets, the present study evaluates the applicability of a simplified version of an existing model-based polarimetric decomposition technique [1] which was developed from Freeman-Durden/Yamaguchi target decomposition methods [10,11].

\subsection{Theoretical Aspects of Polarimetric Decomposition}

Assuming the reflection symmetry for natural media, the coherency matrix [T3] is modeled as a sum of three scattering mechanisms [1,2], namely the surface, the dihedral and the volume scatterings.

$$
\begin{aligned}
& {[\mathrm{T} 3]=\left[\begin{array}{ccc}
T_{11} & T_{12} & 0 \\
T_{12}^{*} & T_{22} & 0 \\
0 & 0 & T_{33}
\end{array}\right]=f_{s}\left[\begin{array}{ccc}
1 & \beta^{*} \operatorname{sinc}(2 \delta) & 0 \\
\beta \operatorname{sinc}(2 \delta) & \frac{1}{2}|\beta|^{2}(1+\operatorname{sinc}(4 \delta)) & 0 \\
0 & 0 & \frac{1}{2}|\beta|^{2}(1-\operatorname{sinc}(4 \delta))
\end{array}\right]} \\
& +f_{d}\left|L_{s}\right|^{2}\left[\begin{array}{ccc}
|\alpha|^{2} & \alpha & 0 \\
\alpha^{*} & 1 & 0 \\
0 & 0 & 0
\end{array}\right]+f_{v}\left[\begin{array}{ccc}
V_{11} & V_{12} & 0 \\
V_{12} & V_{22} & 0 \\
0 & 0 & V_{33}
\end{array}\right]
\end{aligned}
$$

(1) Surface scattering: In Equation (1), the surface scattering mechanism is modeled by the X-Bragg model. The surface roughness term $\delta$ (the empirical value of $\pi / 6$ in [1] is also optimal in our study) is introduced into the X-Bragg model by rotating the coherency matrix around line of sight (LOS). Consequently, in contrast to the classical Bragg model, the X-Bragg model is applicable for a wider range of surface roughness conditions ( $k s<1$ with $k$ and $s$, the wavenumber and the surface $r m s$ height, respectively). In addition, two other parameters are used to describe the surface scattering component: $\beta$ is the normalized difference of the Bragg scattering in $\mathrm{H}$ and $\mathrm{V}$ polarizations and $f_{s}$ is the single scattering amplitude [1]:

$$
\begin{gathered}
\beta=\frac{R_{h}-R_{v}}{R_{h}+R_{v}} \\
f_{s}=0.5 m_{s}^{2}\left|R_{h}+R_{v}\right|^{2}
\end{gathered}
$$


where $m_{s}$ accounts for the microwave attenuation due to the vegetation layer and surface roughness. The Bragg scattering coefficients $\left(R_{h}\right.$ and $\left.R_{v}\right)$ depend on soil dielectric constant $\varepsilon_{s}$ and incidence angle $\theta$ as follows: $R_{h}=\frac{\cos \theta-\sqrt{\varepsilon_{S}-\sin ^{2} \theta}}{\cos \theta+\sqrt{\varepsilon_{S}-\sin ^{2} \theta}}$ and $R_{v}=\frac{\left(\varepsilon_{S}-1\right)\left(\sin ^{2} \theta-\varepsilon_{S}\left(1+\sin ^{2} \theta\right)\right)}{\left(\varepsilon_{S} \cos \theta+\sqrt{\varepsilon_{S}-\sin ^{2} \theta}\right)^{2}}$.

(2) Dihedral scattering: For the dihedral scattering component, it is parameterized using $\alpha$ (the normalized difference of the combined ground-trunk Fresnel reflection in $\mathrm{H}$ and $\mathrm{V}$ polarizations) and $f_{d}$ which is the dihedral scattering amplitude [1]:

$$
\begin{gathered}
\alpha=\frac{R_{g h} R_{t h}-R_{g v} R_{t v} e^{i \varphi}}{R_{g h} R_{t h}+R_{g v} R_{t v} e^{i \varphi}} \\
f_{d}=0.5\left|R_{g h} R_{t h}+R_{g v} R_{t v} e^{i \varphi}\right|^{2}
\end{gathered}
$$

where the Fresnel coefficients are given by: $R_{i h}=\frac{\cos \theta_{i}-\sqrt{\varepsilon_{i}-\sin ^{2} \theta_{i}}}{\cos \theta_{i}+\sqrt{\varepsilon_{i}-\sin ^{2} \theta_{i}}}$ and $R_{i v}=\frac{\varepsilon_{i} \cos \theta_{i}-\sqrt{\varepsilon_{i}-\sin ^{2} \theta_{i}}}{\varepsilon_{i} \cos \theta_{i}+\sqrt{\varepsilon_{i}-\sin ^{2} \theta_{i}}}$ and the subscript $i$ denotes ground $(g)$ and trunk ( $t$ ), as in Equations (4) and (5), with $\theta_{g}=\pi / 2-\theta_{s}$. In addition, the dihedral scattering amplitude $f_{d}$ is corrected from an attenuation factor $\left(L_{s}\right)$ due to surface roughness [1]: $L_{s}=\exp \left(-2 k^{2} s^{2} \cos ^{2} \theta\right)$ where $k$ is the wave number and $s$ is the RMS height of soil roughness.

(3) Volume scattering: For the volume scattering component, three canonical orientation cases are assumed, namely: vertical, random and horizontal [11]. They lead respectively to the following volume coherency matrices $\left[\mathrm{Tv}_{\mathrm{v}}\right],\left[\mathrm{Tv}_{\mathrm{r}}\right]$ and $\left[\mathrm{Tv}_{\mathrm{h}}\right][1]$ :

$$
\begin{array}{lc}
{\left[\mathrm{Tv}_{v}\right]=f v\left[\begin{array}{ccc}
V_{11} & V_{12} & 0 \\
V_{12} & V_{22} & 0 \\
0 & 0 & V_{33}
\end{array}\right]} & {\left[\operatorname{Tv}_{v}\right]=\frac{f v}{30}\left[\begin{array}{ccc}
15 & 5 & 0 \\
5 & 7 & 0 \\
0 & 0 & 8
\end{array}\right]} \\
{\left[\mathrm{Tv}_{r}\right]=\frac{f v}{4}\left[\begin{array}{lll}
2 & 0 & 0 \\
0 & 1 & 0 \\
0 & 0 & 1
\end{array}\right]} & {\left[\operatorname{Tv}_{h}\right]=\frac{f v}{30}\left[\begin{array}{ccc}
15 & -5 & 0 \\
-5 & 7 & 0 \\
0 & 0 & 8
\end{array}\right]}
\end{array}
$$

Finally, using Equation (1), the scattering powers of surface (single bounce) $P_{S}$, dihedral (double bounce) $P_{D}$ and volume scattering $P_{V}$ are calculated as [1]:

$$
\begin{gathered}
P_{S}=f_{S}\left(1+|\beta|^{2}\right) \\
P_{D}=f_{d}\left|L_{s}\right|^{2}\left(1+|\alpha|^{2}\right) \\
P_{V}=f_{v}\left(\mathrm{~V}_{11}+\mathrm{V}_{22}+\mathrm{V}_{33}\right)
\end{gathered}
$$

\subsection{Simplified Polarimetric Decomposition-Based Soil Moisture Retrieval}

This paper only focused on the analysis of the surface scattering component (after removing the volume contribution appropriately) to retrieve soil moisture. The idea stemmed from the previous study [1], which indicated that few pixels could be inverted from the dihedral scattering component. Furthermore, the soil moisture retrieval from the dihedral scattering component is based on the two-dimensional minimization in the $f_{d}-\alpha$ plane, since the dihedral scattering component is dependent on both the soil and vegetation dielectric constant. Nevertheless, the dihedral scattering intensity $f_{d}$ is disturbed by the microwave propagation through the vegetation canopy. Therefore, $f_{d}$ must be appropriately compensated for a better retrieval accuracy [1]. Otherwise, the retrieved soil moisture from the dihedral scattering component is underestimated. In addition, an ambiguity 
is presented in the dihedral component around incidence angle $45^{\circ}$ to separate the contributions of vegetation and soil. Consequently, this paper aims to simplify the polarimetric-based soil moisture retrieval [1] by using only the surface scattering component, once the volume scattering contribution was removed. Figure 4 presents a flowchart of the algorithm described as follows:

- $\quad$ First, the study site is categorized into bare soils and vegetated soils. The X-Bragg model [22] which is an extended Bragg model in terms of roughness conditions is adopted for bare soil retrievals [1].

- For the vegetated soils, the orientation of the crop spatial distribution is determined for each pixel according to the $\operatorname{Pr}=10 \cdot \log 10\left(S_{v v} S_{v v}^{*} / S_{h h} S_{h h}{ }^{*}\right)$ value [11].

- Two values of volume scattering intensity $\left(f v_{1}, f v_{2}\right)$ are computed by solving the equation system in Equation (1) [1].

- Then, in order to restrict the negative powers of the different scattering components, the theory of non-negative eigenvalues [23] is considered for the ground component by setting eigen $(\mathrm{Tg})=0$. The resulted three values of volume scattering intensity $\left(f v_{3}, f v_{4}\right.$, and $\left.f v_{5}\right)$ are compared to the previous estimated values $\left(f v_{1}, f v_{2}\right)$. The appropriate estimation of volume scattering intensity is considered as the minimum value of these five calculated volume scattering intensities $\left(f v_{1}, f v_{2}\right.$, $f v_{3}, f v_{4}$, and $\left.f v_{5}\right)$ [2].

- Ground scattering component $[\mathrm{Tg}]$ is then obtained by subtracting the appropriate volume component from the measured coherency matrix.

- For a given field, only the pixels corresponding to dominant surface scattering (satisfying the condition $\left.\operatorname{Re}\left(\mathrm{S}_{\mathrm{hh}} \mathrm{S}_{\mathrm{vv}}{ }^{*}\right)>0\right)$ are selected to estimate the soil moisture. An additional physical constraint $-1<\beta<0$ must be satisfied.

- Finally, a minimization process is implemented for deriving the soil dielectric constant from $\beta_{\text {data }}$. Then, the dielectric constant is converted into soil moisture using [24].

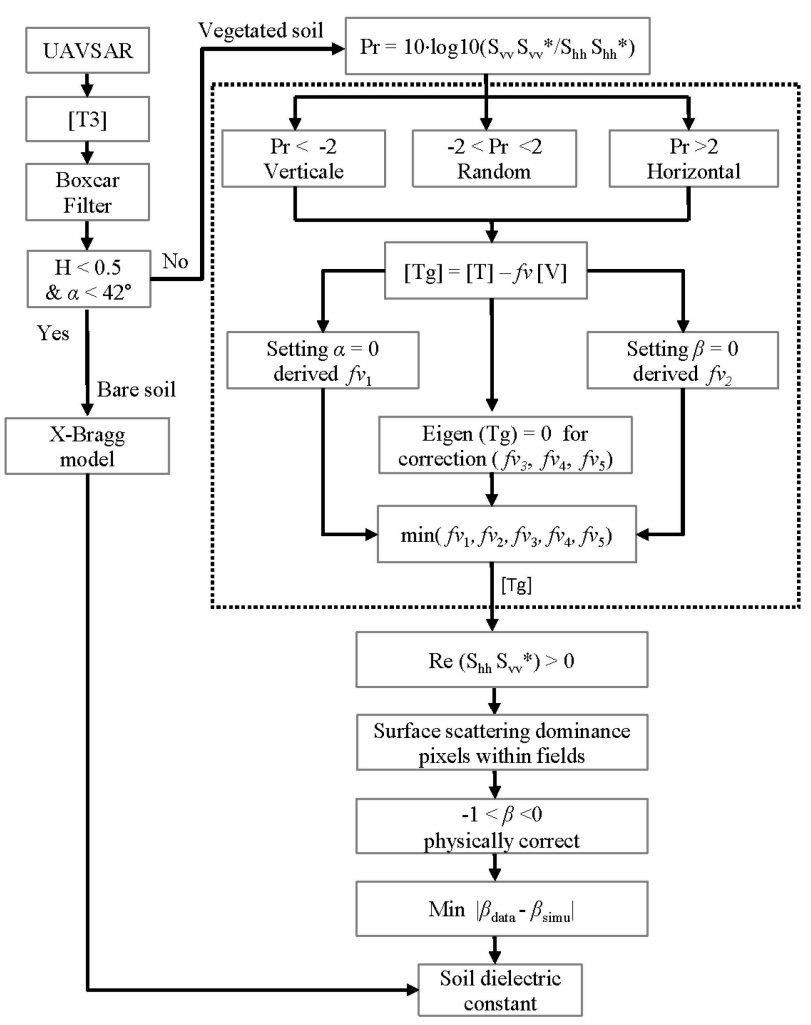

Figure 4. The simplified polarimetric-based soil moisture retrieval over agricultural fields. The dashed box indicates the process for removing the volume scattering component. 
Therefore, in this study, the unique feature lies in the pixel selection strategy for soil moisture retrieval using the surface scattering component. In this way, the potential of surface component inversion with only one dielectric constant, without any contribution of the dihedral component with two dielectric constants, is investigated. To summarize, for each individual agricultural field, the pixels are selected for soil moisture retrieval if they satisfy simultaneously these two conditions:

- The surface scattering is dominant in the remaining ground scattering matrix after removing the volume contribution.

- The values of $\beta_{\text {data }}$ extracted from UAVSAR data are physically correct

\subsection{Assessement of the Volume Scattering Removal Using Entropy and $\alpha$ Angle}

Furthermore, it is well known that an important aspect of the abovementioned soil moisture retrieval algorithm over vegetated soils relies on the modeling of the volume component. Thus, in this study, the success in modeling and removing the volume scattering is evaluated by using the Cloude-Pottier decomposition method [20,25]. In this decomposition, the scattering entropy $(\mathrm{H})$ and the mean scattering mechanism indicator ( $\alpha$ angle) are derived from the eigenvalues $\lambda_{i}(i=1,2,3)$ and the corresponding eigenvectors $e_{i}$ of the coherency matrix:

$$
\text { Entropy }=\sum_{i=1}^{3}-p_{i} \log _{3} p_{i} \quad \text { and } \quad \alpha=\sum p_{i} \operatorname{acos}\left(\left|e_{i 1}\right|\right)
$$

where the normalized eigenvalue $p_{i}$ and the eigenvector $e_{i}$ are given by $p_{i}=\lambda_{i} / \sum_{i=1}^{3} \lambda_{i}$ and $e_{i}=\left[e_{i 1}, e_{i 2}, e_{i 3}\right]$.

This eigen-based decomposition algorithm is applied to both the original coherency matrix [T3] and the ground coherency matrix [Tg]. In order to evaluate the success in modeling the volume scattering, the 2-D distributions of the investigated fields before and after removing the volume component are compared using the entropy / $\alpha$ plane.

\subsection{Statistical Index for the Retrieval Process Analysis}

Finally, the performances of the retrieval procedure are assessed based on Pearson product moment correlation coefficient and RMSE [26]:

$$
\begin{gathered}
R=\frac{\sum_{i=1}^{N}\left(\mathrm{O}_{i}-\overline{\mathrm{O}}\right)\left(\mathrm{P}_{i}-\bar{P}\right)}{\sqrt{\sum_{i=1}^{N}\left(\mathrm{O}_{i}-\overline{\mathrm{O}}\right)^{2}} \sqrt{\sum_{i=1}^{N}\left(\mathrm{P}_{i}-\bar{P}\right)^{2}}} \\
R M S E=\sqrt{\frac{1}{N} \sum_{i=1}^{N}\left(\mathrm{O}_{i}-P_{i}\right)^{2}}
\end{gathered}
$$

where the index $i$ describes the investigated day, $O_{i}$ is the mean value of the measured soil moisture for one crop type on a given day, $P_{i}$ is the mean value of the retrieved soil moisture from the surface scattering component for that crop type, $\bar{O}$ is the mean value of the measured soil moisture for one crop type during all of the investigated days, $\bar{P}$ is the mean value of the retrieved soil moisture for one crop type during all of the investigated days, and $N$ is the number of acquisition dates. The $R$ is used to quantify the level of agreement between model predictions and ground measurements, while the RMSE is used to quantify the magnitude of the modeling average error.

The next section describes the results obtained from the simplified polarimetric-based soil moisture retrieval and the evaluation of the method. 


\section{Results and Discussion}

This section presents the results obtained from the application of the simplified polarimetric soil moisture retrieval method to the temporal datasets of UAVSAR acquired during SMAPVEX12. To understand and evaluate the advantages and the limitations of this algorithm, the temporal variations of the scattering mechanisms (before and after the removal of the vegetation volume component) are first analyzed. Then, soil moisture retrieval results are presented and discussed.

\subsection{Temporal Variation of Scattering Mechanisms}

Figure 5 shows the false color composite of the normalized surface, dihedral, and volume scattering mechanisms (Equation (7)) for Julian days 169 (17 June 2012), 185 (3 July 2012), and 199 (17 July 2012) corresponding to three representative days (beginning, middle, and end of the campaign). A classification map [18] of the considered five crop types is provided to relate the scattering characteristics to crop types (on this map, the areas in white color are covered by other crops and the forested site). Generally, it can be noted that the surface scattering intensity tends to decrease from June to July 2012, since the fast crop development during the investigation period and the well-developed crops' structure (height and biomass are increased) in July reduce the penetration depth of the microwave signal. This decrease of the surface scattering component is especially pronounced in the near range, as the single scattering component is more significant at low incidence angle (corresponding to near range). A strong dihedral scattering component, like in [1], is observed at the beginning of the campaign (Figure 5a) for several fields, mainly those covered by corn. Indeed, according to the SMAPVEX12 ground measurements, the vegetation height and biomass are still low at this time, leading to a double bounce between vegetation stalk and the underlying soil. At mid-campaign, the dihedral scattering component becomes less significant due to the developed leaf layer and the increased complexity of vegetation structure which reduce the dihedral scattering mechanism. The volume scattering component is predominant over the fields covered by canola, wheat and corn.

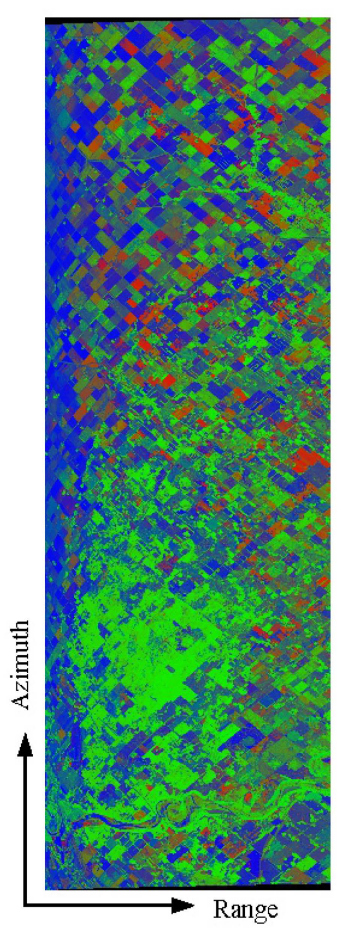

(a)

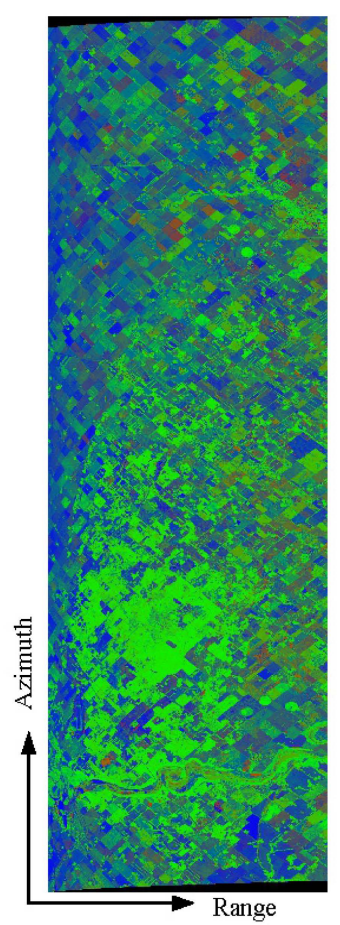

(b)

Figure 5. Cont. 


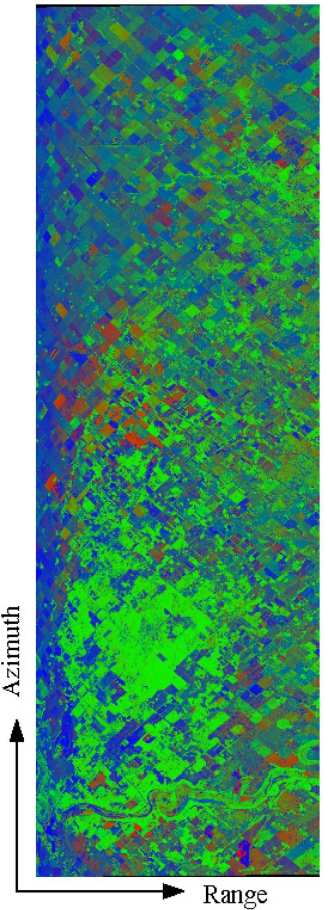

(c)

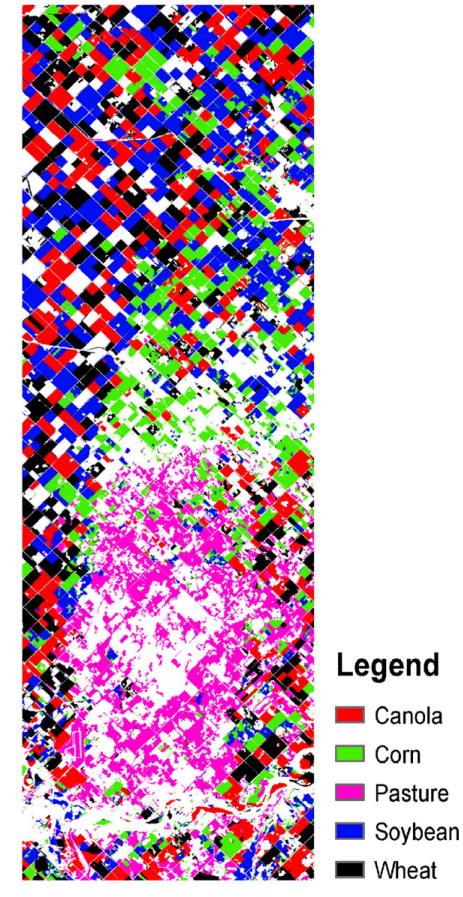

(d)

Figure 5. RGB color composition of the normalized three scattering mechanisms for Julian day (a) 169 (17 June 2012); (b) 185 (3 July 2012); (c) 199 (17 July 2012). Dihedral scattering power in red, volume scattering power in green and surface scattering power in blue. The incidence angle in the range direction varies from $25^{\circ}$ to $65^{\circ}$. (d) Classification map of the considered five crop types (the areas in white color are covered by other crops and the forested site).

For different crop types, Figure 6 shows the temporal variation of each scattering mechanism (surface, dihedral, and volume scatterings) derived as the mean value of the normalized scattering power. The backscattering mechanisms of soybean are in accordance with the temporal variation of plant penology (Figure 3), which indicates the increase in volume scattering power and the decrease in surface scattering power. As the vegetation water content of soybean is low during the developing stage considered in this study (less than $1 \mathrm{~kg} / \mathrm{m}^{2}$ ), the temporal evolution of its volume scattering is mainly affected by the changes in soybean structure. Regarding the corn, Figure $6 \mathrm{~b}$ shows that its dihedral scattering power is significant at the beginning of the campaign as a result of the already developed corn stalk supporting only a few leaves. From Julian day 175 (June 23), the dihedral scattering component decreases due to the well-developed corn leaves which attenuate the electromagnetic waves (followed by a decline of surface scattering component from Julian day 177 to 187). For the pasture, the temporal evolution of scattering mechanisms is quiet stable, which is probably due to the low and stable biomass indicated by the ground measurements. For wheat fields, the increase in surface scattering (Figure 6a) is in agreement with the quasi stable wheat's water content value $\left(2.2 \mathrm{~kg} / \mathrm{m}^{2}\right)$ and its increasing height [1]. This corresponds to a vegetation drying out, which enhances the surface scattering and decreases the volume scattering (Figure 6c) due to a more pronounced signal penetration.

For the fields covered by canola, the surface scattering power increases while the volume scattering power decreases during the growing period (Figure 6). These temporal behaviors which seem unexpected are closely related to the temporal evolution of height, biomass and vegetation water content (Figure 3) as well as to the correlation between these parameters. Indeed, during the crop growth cycle, canola's height, biomass and vegetation water content increase until reaching the mature stage which is then followed by a drying out process. Therefore, the decreasing vegetation water 
content from the maturation stage leads to a decrease in the volume scattering and an increase in the surface scattering. Consequently, due to the combined effect of the biomass, height and the vegetation water content on the volume scattering, the latter does not increase during the growing season as expected; in turn, neither does the surface scattering during the growing season. In addition, other reasons arising from the polarimetric decomposition can explain these results $[1,2]$, particularly those obtained before the canola's drying out. For instance, the high and sophisticated temporal changes in the shapes and structures of canola during the considered phenological stage may not be fully exploited by the only three fixed volume coherency matrices.

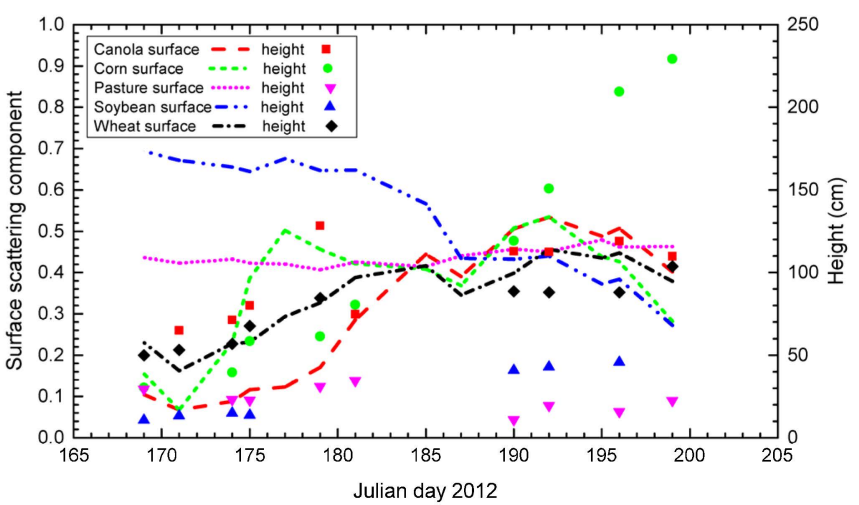

(a)

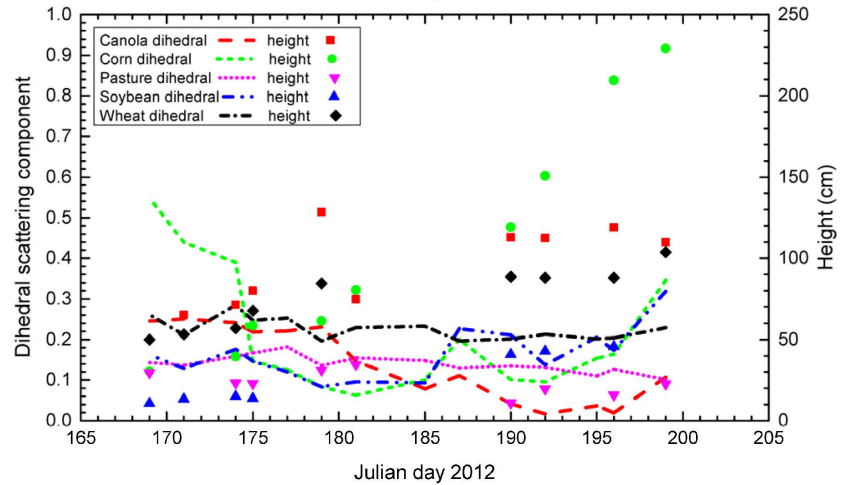

(b)

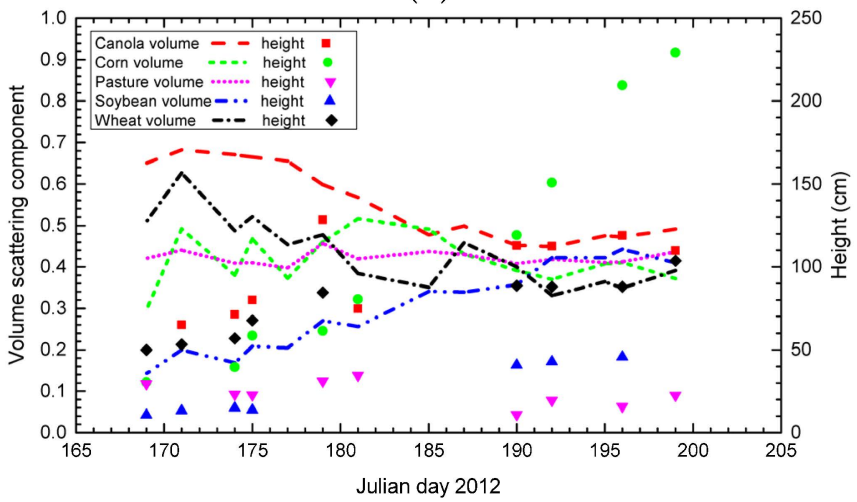

(c)

Figure 6. Temporal variation of normalized scattering powers of (a) surface scattering, (b) dihedral scattering and (c) volume scattering component for different crop types. The points (corresponding to right $y$-axis) shows the height of different crop types.

The scattering characteristics are affected by several factors including the vegetation water content, height, biomass and density. The scatterplots in Figures 7 and 8 present the behaviors of the volume 
and surface scatterings with respect to vegetation water content. They show that as the vegetation water content increases, the volume scattering power increases while the surface scattering power decreases respectively. Different volume/surface scattering behaviors are obtained even for similar vegetation water content values due to the combined effects of the influencing factors. Furthermore, the dynamic of scattering mechanisms to vegetation water content is significantly dependent on the crop growing stage. The low and no correlations observed between the vegetation water content and volume (or surface scattering) during the middle and the end of the campaign (Figure $7 \mathrm{~b}, \mathrm{c}$, Figure 8b,c), respectively, suggest the loss of explanatory power of the adopted linear regression.

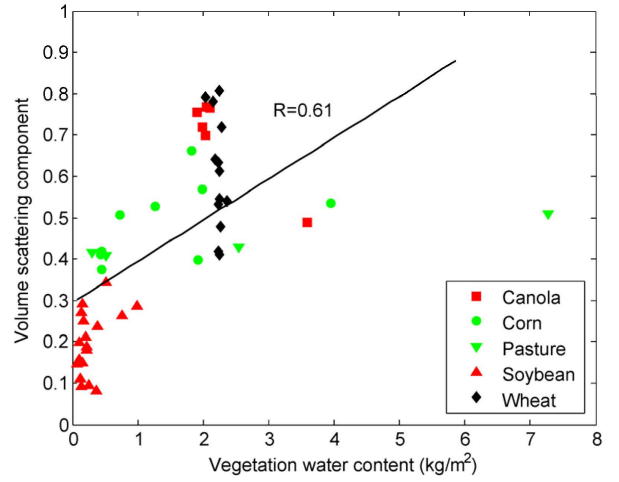

(a)

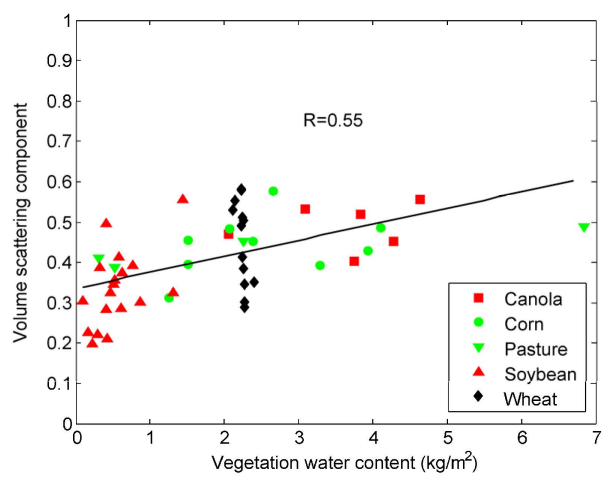

(b)

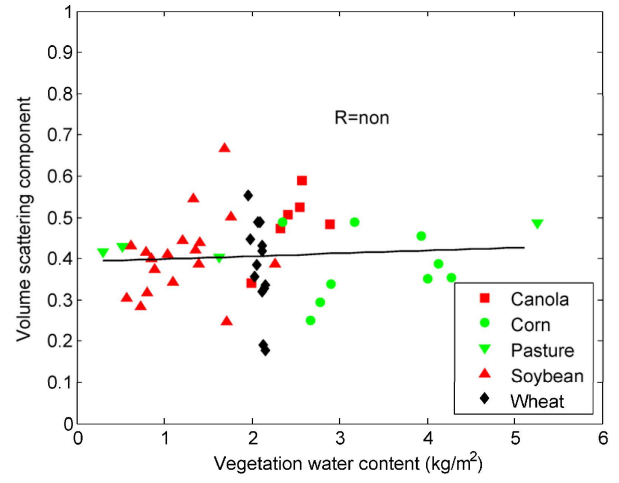

(c)

Figure 7. Correlation analysis of vegetation water content and volume scattering component for Julian day (a) 169 (17 June 2012); (b) 185 (3 July 2012); (c) 199 (17 July 2012).

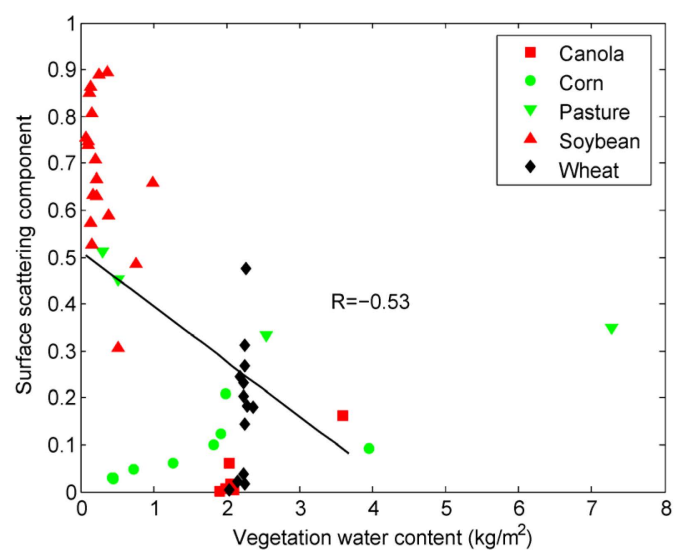

(a)

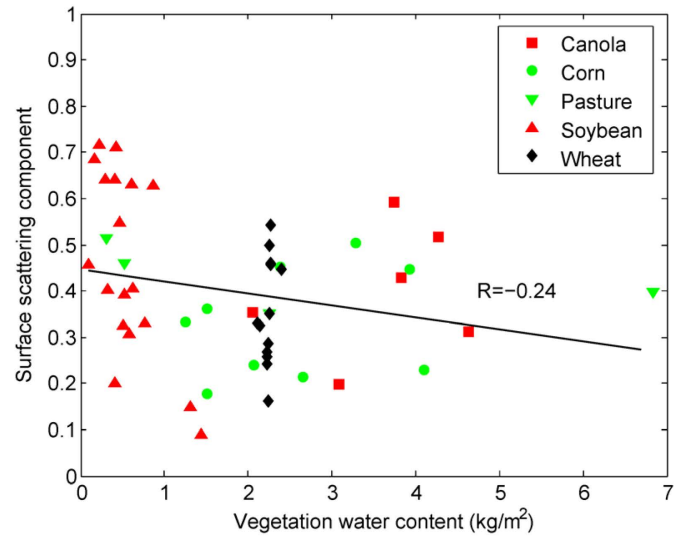

(b)

Figure 8. Cont. 


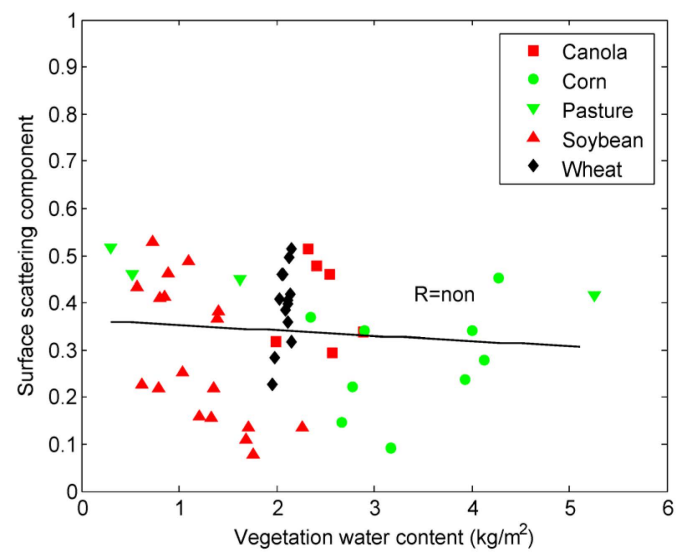

(c)

Figure 8. Correlation analysis of vegetation water content and surface scattering component for Julian day (a) 169 (17 June 2012); (b) 185 (3 June 2012); (c) 199 (17 July 2012).

\subsection{Evaluation of the Modeling of the Volume Scattering and Its Removal from the Measured Coherency Matrix}

In this paper, a main challenge lies in the modeling of the vegetation contribution and its removal in order to better retrieve the soil moisture from the remaining surface scattering component. To understand the vegetation scattering, the polarimetric parameters entropy and $\alpha$ scattering angle (Section 3.3) are used to build a 2-D plane, which is subsequently divided into nine zones for different scattering characteristics. For comparison purposes, for several dates, Figures 9 and 10 show the results of 2-D statistical distribution density of crops obtained before and after the removal of the volume component respectively, with an over plot of the mean values of entropy and $\alpha$ angle for each test field. The color represents the statistical distribution density (from low density in blue to high density in red), while the dashed lines denote the boundary of the nine divided scattering characteristics. Through the comparison, the effect of volume contribution can be understood.

Figure 9 shows that soybean fields present the highest dynamic, especially for its entropy values. It can be seen in Figure 9a, which corresponds to the beginning of campaign, that the soybean fields are dominated by the surface scattering ( $\alpha$ angle is less than $45^{\circ}$ ), and they are well discriminated from the other crop types. With the growth of the soybean, the entropy and the $\alpha$ angle increase due to changes in crop structure (Figure 9b). At the end of the campaign, when the crops are in the mature stage, Figure $9 \mathrm{c}$ shows that the field distribution is more clustered, thus hampering any discrimination between the crops.

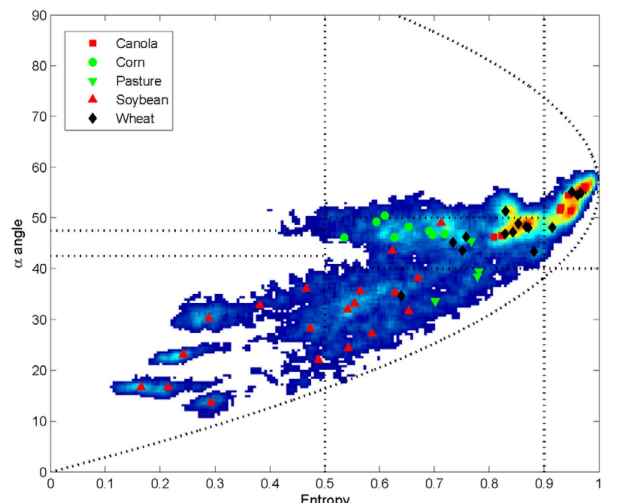

(a)

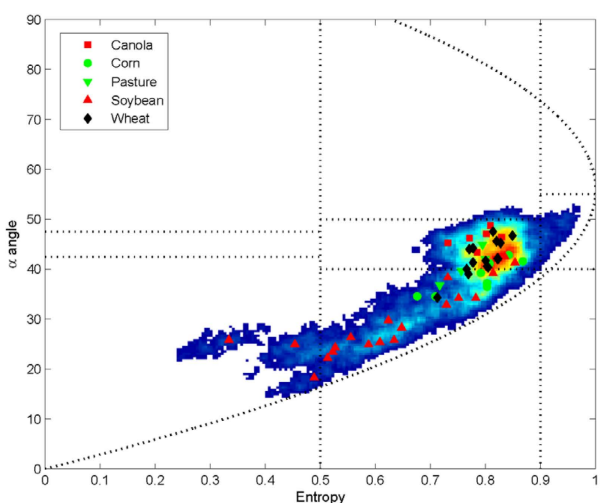

(b)

Figure 9. Cont. 


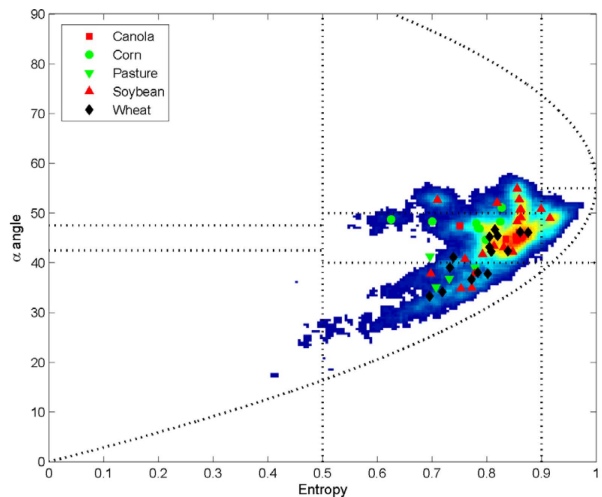

(c)

Figure 9. Distribution of fields on entropy / $\alpha$ plane before the removal of the volume component on Julian day (a) 169 (17 June 2012); (b) 185 (3 July 2012); (c) 199 (17 July 2012).

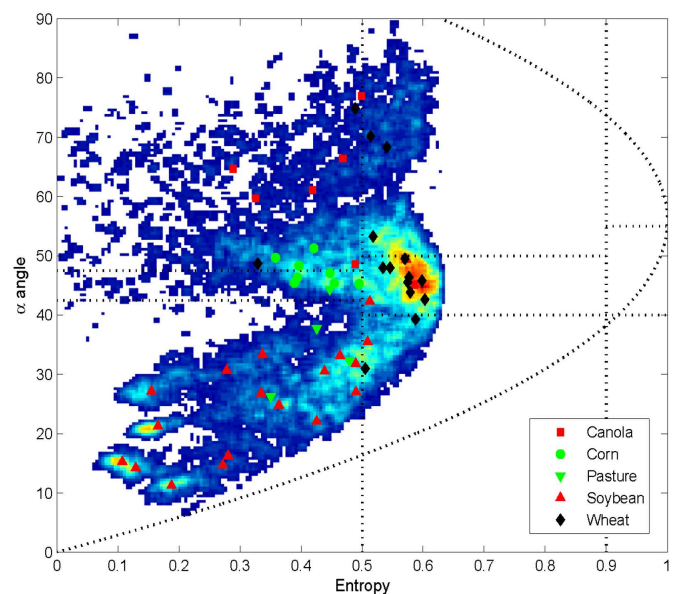

(a)

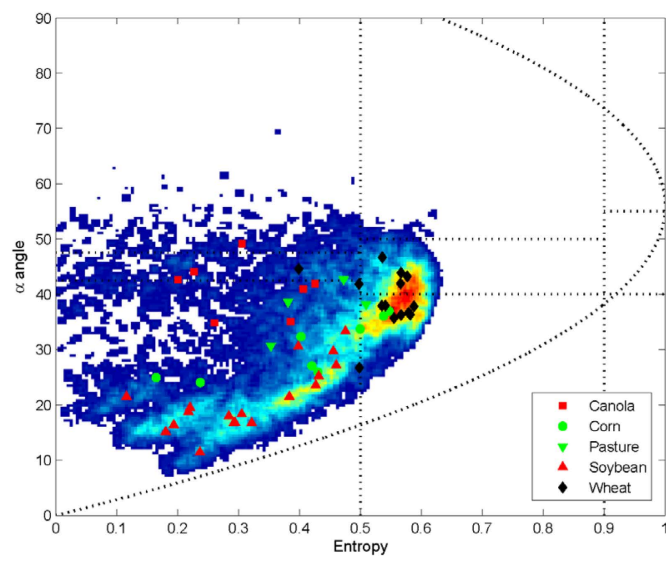

(b)

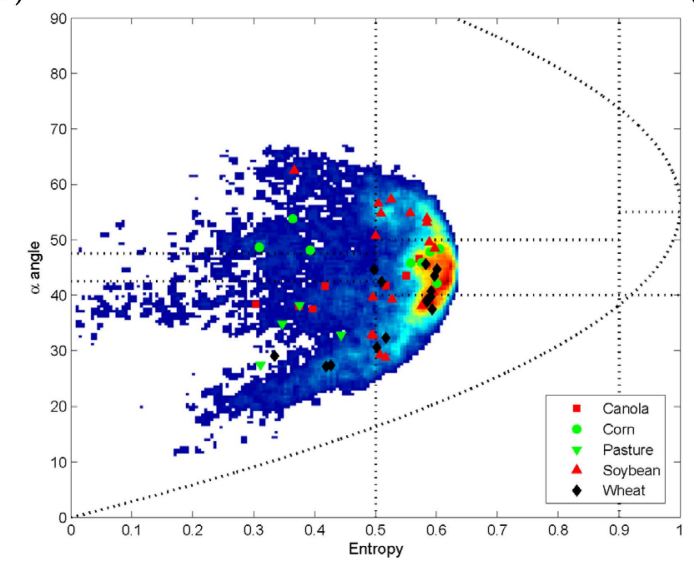

(c)

Figure 10. Distribution of fields on entropy / $\alpha$ plane after the removal of the volume component on Julian day (a) 169 (17 June 2012); (b) 185 (3 July 2012); (c) 199 (17 July 2012).

Comparing Figures 9 and 10 a decrease in entropy values clearly appears for all crops. This result is expected since the remaining ground coherency matrix $[\mathrm{Tg}]$ used to generate the Figure 10 represents the surface and dihedral scatterings, and consequently provides lower entropy than the results (Figure 9) obtained from the measured coherency matrix [T3]. Nevertheless, in Figure 10, some of the scattering $\alpha$ angles which are still located within the dipole/volume scattering region are probably 
related to the residual volume scatterings. These can be explained not only from the limitation of this polarimetric decomposition algorithm using fixed volume orientation cases, but also from the strict narrow criterion on $\alpha$ angle. Indeed, $\alpha$ angle used to characterize the scattering mechanisms stems from a purely empirical segmentation of the entropy / $\alpha$ plane $[20,25]$.

Furthermore, the performance of the volume removal depends on both crop phenological stage and crop types due to different plant geometry and density. Better results were obtained for moderate vegetation height and biomass condition. For example, during mid-campaign, the peak value of 2-D distribution density is shifted significantly into the surface scattering region in the entropy/ $\alpha$ plane (Figure 10b). In contrast, at the beginning and the end of the campaign, the volume contribution can only be partially removed. Indeed, in this study, the vegetation structure is modeled as dipoles considering three fixed orientation cases. However, the low vegetation (lacking strict stem) and the high vegetation status (with abundant leaves and ears) seem to be represented by a spherical-like shape [1]. As for the effect of crop types on the performance of the volume scattering modeling and removal, good results are obtained for soybean and pasture. We expect therefore that these crops match better with the predefined and fixed volume coherency matrix. Nevertheless, the volume contribution of wheat and canola can only be partially removed by the proposed volume model (Equation (6)). It is likely that their orientations are not sufficiently represented by the only three fixed volume components. In order to further analyze the effect of the three fixed vegetation orientation cases on the removal of the volume component, the exemplary results obtained over canola fields on day 185 (3 July 2012) are compared through the entropy / $\alpha$ plane presented in Figure 11. For this crop and at this phenological stage particularly, even though there is no clear tendency in the results shown in Figure 11, vertical orientation seems to provide the best one. Therefore, any failure in considering the appropriate crop orientation will negatively impact the modeling and the removal of the volume component.

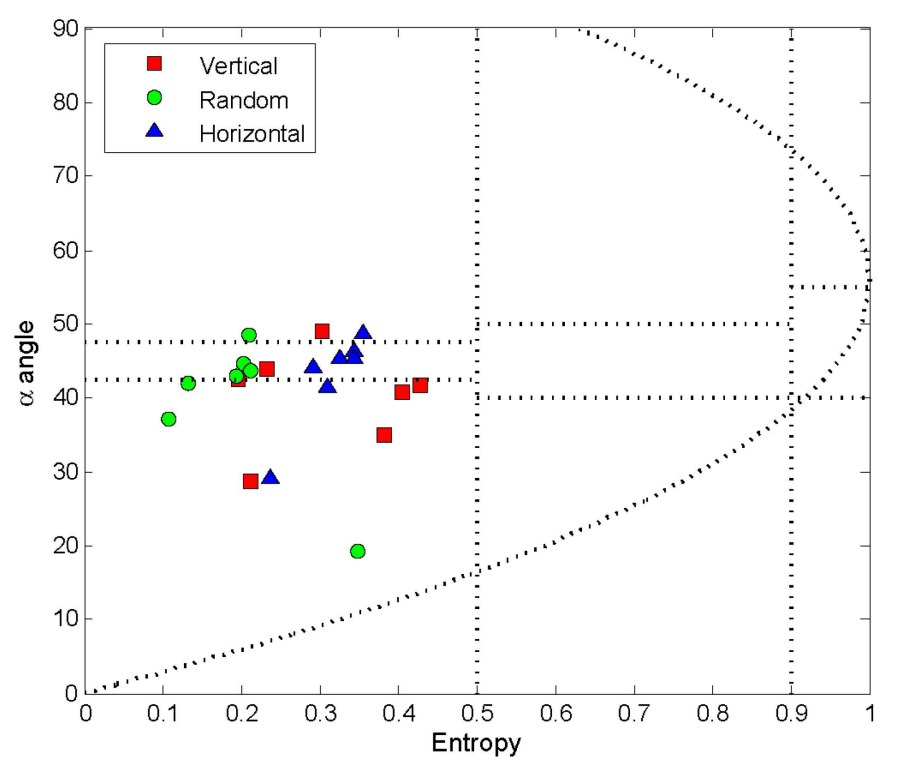

Figure 11. Distribution of canola fields on entropy / $\alpha$ plane after the removal of volume scattering component on Julian day 185 (3 July 2012) for three vegetation orientations (vertical, horizontal and random).

\subsection{Soil Moisture Retrieval Results}

They are obtained from the fields characterized by a dominant surface scattering component, after the removal of the volume scattering component.

(1) Percentage of dominant surface scattering after removing the volume component: In order to ensure both the retrieval accuracy and spatial inversion rate, a given field was selected for soil moisture inversion, if more than $10 \%$ of its area was covered by pixels satisfying the dominant surface scattering 
criteria. Since for canola, corn and wheat's fields the dominant surface scattering cases were low at the beginning of the campaign (Figure 12), thresholding the dominant surface scattering cases at $10 \%$ allowed retrieval of the soil moisture for almost all the crops. However, as the soil moisture retrieval algorithm is a simplified one, which is only based on the dominant surface scattering, the accuracy is compromised in the conditions of the highly dominant dihedral scattering component. Consequently, for these fields characterized by more than $10 \%$ of dominant surface scattering cases, a spatial average of soil moisture was computed from the retrieved soil moisture obtained over the pixels with the dominant surface scattering. Considering Figure 12 which presents the percentage of the dominant surface scattering case for different crop types, the surface scattering component could be used as inputs in the retrieval process, except for canola fields before Julian day 173 (June 21), when the dominant surface scattering case is lower than $10 \%$. Due to the complementarity between the dominant surface scattering and the dihedral scattering component in the remaining signal, Figure 12 also indicates an important dihedral scattering component for canola, wheat and corn from Julian day 169 to 178 (from June 16 to 26). Under such conditions, less performance of the simplified polarimetric soil moisture retrieval algorithm will be obtained, which is mainly due to the over-subtraction of volume scattering contribution.

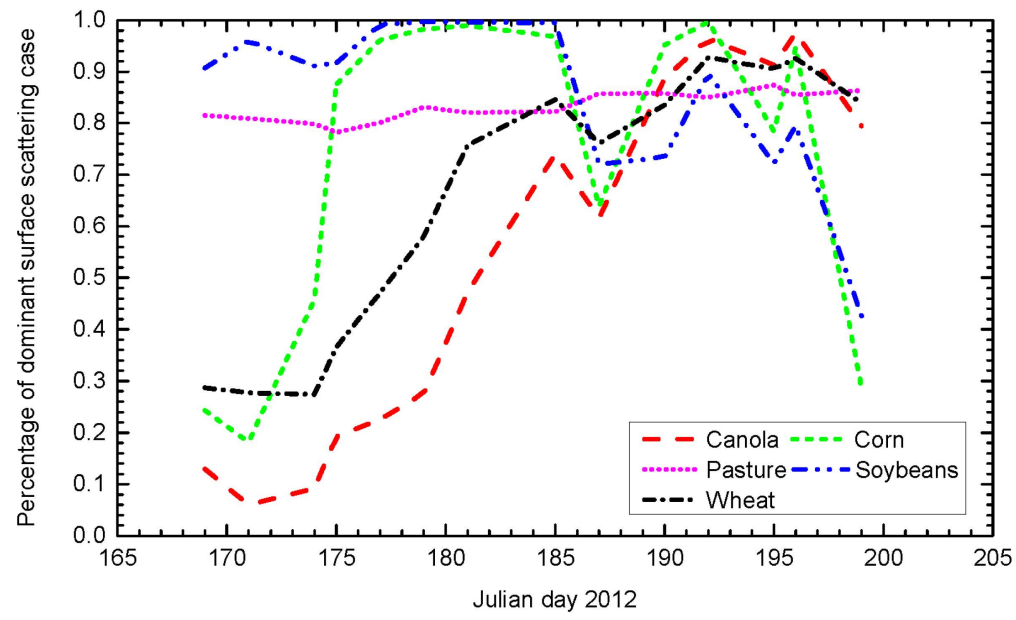

Figure 12. Percentage of dominant surface scattering case after removing volume scattering component, for different crop types.

(2) Evaluation of the simulated $\beta$ parameter: This step is important since the soil moisture is derived from the normalized difference of Bragg scattering in $\mathrm{H}$ and V polarization $\beta$ (Figure 4). Figure 13 compares the $\beta_{\text {data }}$ values which are derived from UAVSAR data with corresponding simulation values obtained using the known incidence angles of UAVSAR and the field average of the measured soil moisture as inputs. In Figure 13, each $\beta_{\text {data }}$ value is a field average for a given sampling field (it is computed by averaging the values of all the pixels within the targeted field, except the pixels near the field boundary to remove boundary effects). Disagreements are found between the simulated and the derived $\beta$ parameter for canola, wheat and corn crops, while for soybean and pasture the results of $\beta_{\text {data }}$ and $\beta_{\text {simu }}$ match better. This result is in line with the analysis of the scattering mechanisms conducted in Section 4.2, specifically the limitations observed in the volume scattering modeling for canola and wheat and its good performance for soybean and pasture. However, for soybean and pasture, the weak deviation observed between the simulated and the derived values of $\beta$ confirms the ability of the surface and volume scattering formulations, as described in [1], to model the phenological development of short vegetation such as soybean and pasture. Therefore, it is important to highlight that the applicability of the simplified polarimetric soil moisture retrieval algorithm is dependent on both the crop type and the crop development stage. 


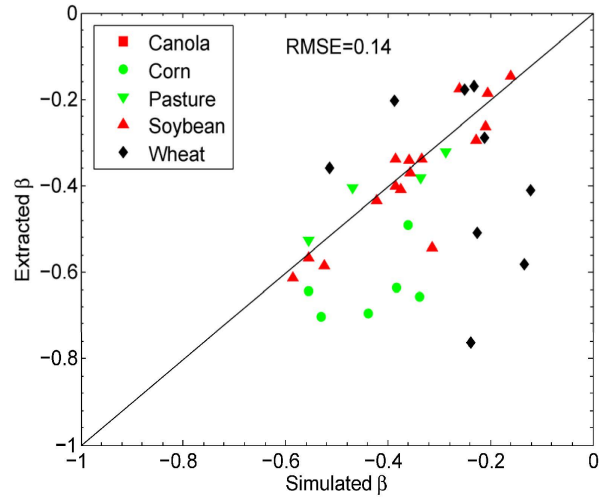

(a)

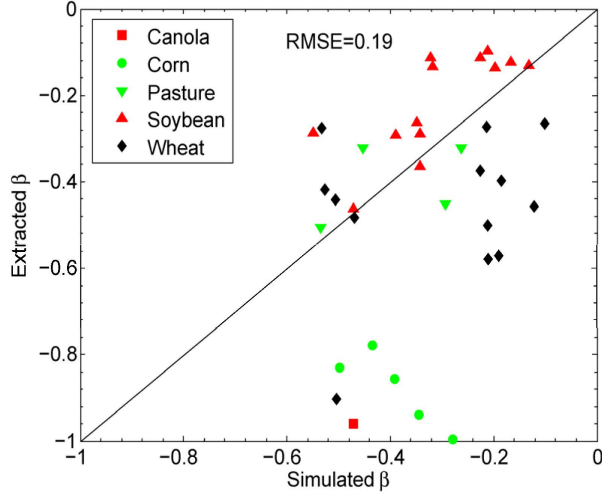

(b)

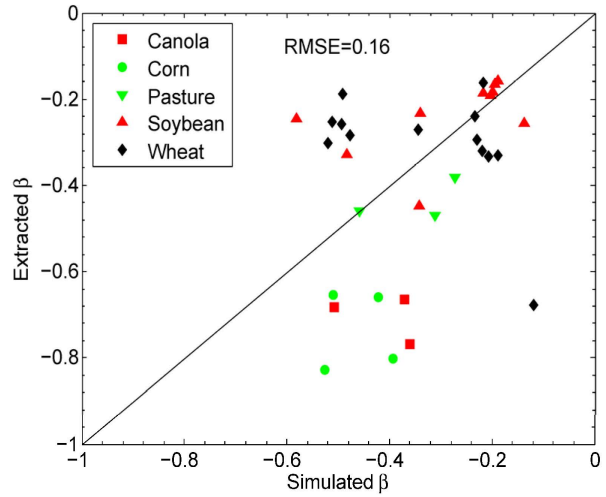

(c)

Figure 13. Comparison between simulated and measured $\beta$ on Julian day (a) 169 (17 June 2012); (b) 185 (3 July 2012); (c) 199 (17 July 2012).

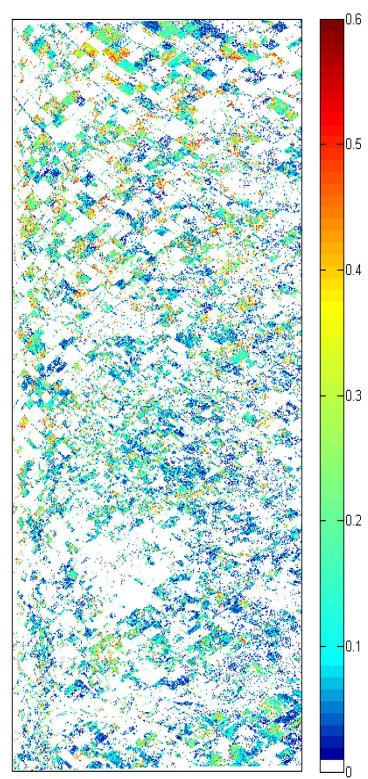

(a)

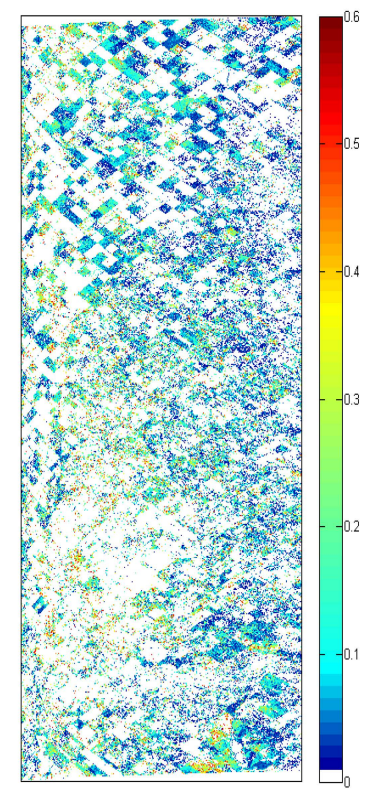

(b)

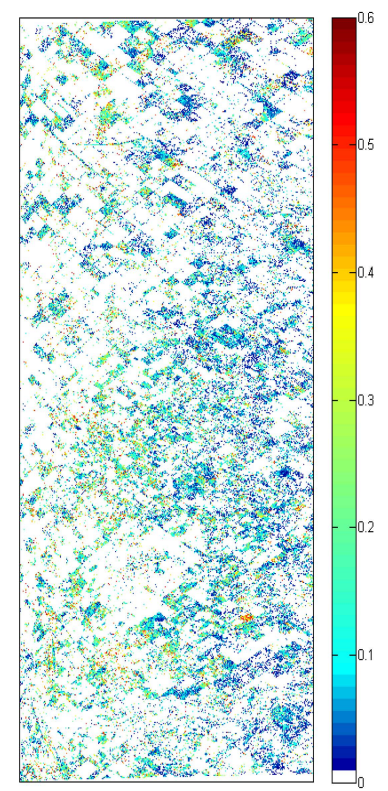

(c)

Figure 14. Spatial distribution of the retrieved soil moisture on Julian day (a) 169 (17 June 2012); (b) 185 (3 July 2012); (c) 199 (17 July 2012).

(3) Analysis of the retrieved soil moisture from the surface scattering component: Figure 14 presents the maps of the retrieved soil moisture for the beginning, middle and end of the agricultural campaign, 
while the invalid pixels are set to white color. Two main reasons can explain these invalid pixels: First, some pixels are characterized by a dominant dihedral scattering after the removal of the volume component. Indeed, in this study, the dihedral component is disregarded due to its ambiguity and disturbance by the wave propagation (the dihedral intensity $f_{d}$ needs to be compensated properly $[1,2]$ ) as well as the low improvement in the soil moisture inversion rate that could be obtained. Second, for some pixels characterized by a dominant surface scattering, the corresponding $\beta$ value is less than -1 , which is non-physically correct [1]. However, the range (5\% to $50 \%)$ of the retrieved soil moisture observed in Figure 14 is in agreement with that of the in situ soil moisture measurements [18]. Furthermore, while some inversion results are provided as field-average values [5], it is interesting to underline the ability of this algorithm to inform about the spatial variability in soil moisture at the field scale (Figure 14). As for the retrieval rate in Figure 15, it varies from $26 \%$ to $38 \%$ before the mature stage of the crops and then decreases, thereby leading to high amount of white pixels in Figure 14c.

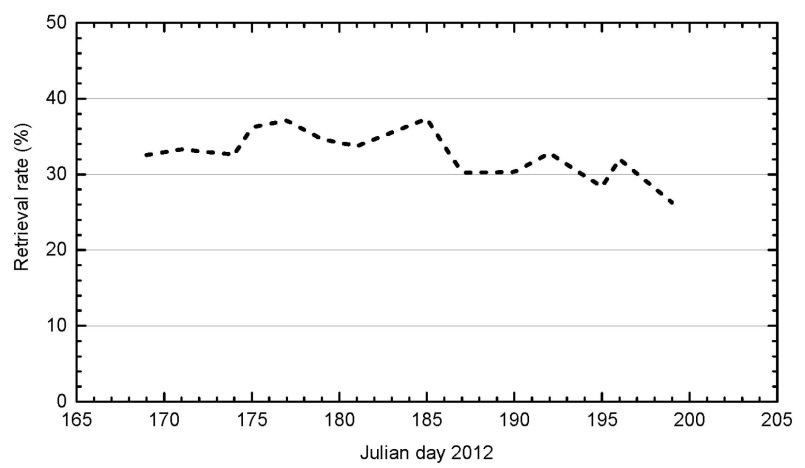

Figure 15. The retrieval rate by using surface scattering component.

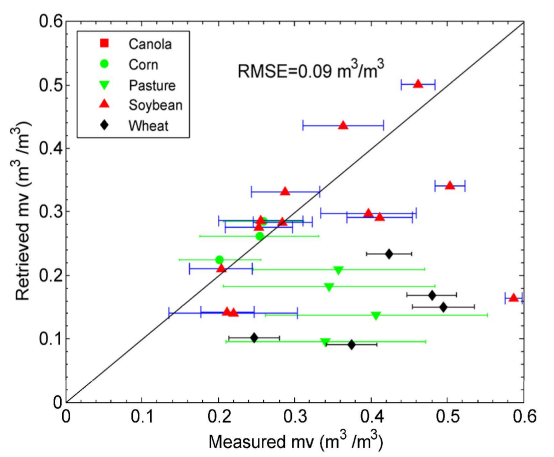

(a)

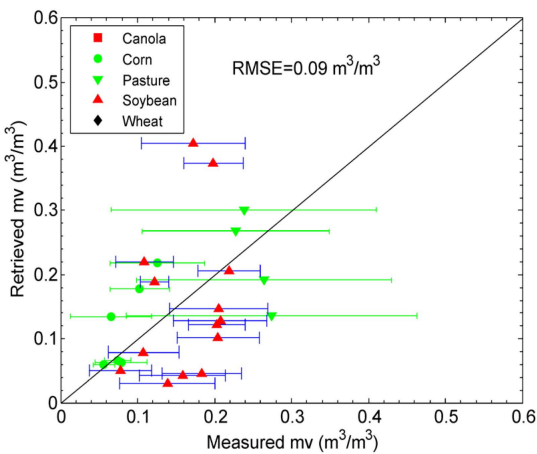

(b)

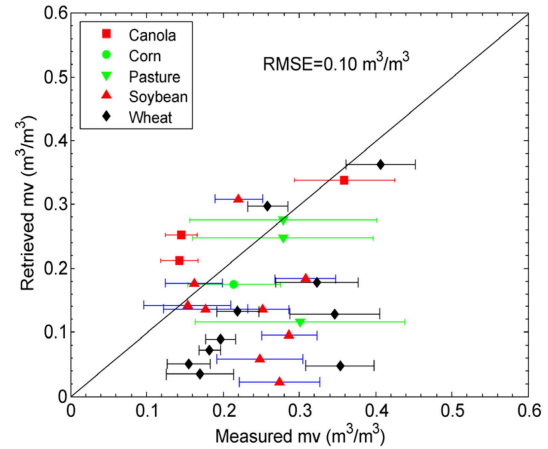

(c)

Figure 16. Comparison between the retrieved and measured soil moisture on Julian day (a) 169 (17 June 2012); (b) 185 (3 July 2012); (c) 199 (17 July 2012). 
A quantitative analysis is also conducted by comparing the mean values of the retrieved soil moisture on each field with the in situ soil moisture measured during the SMAPVEX12 experiment. However, in agreement with the scattering mechanism analysis (Section 4.2) and $\beta$ simulation values (Figure 13), Figure 16 shows that better results are obtained over the fields covered by soybean and pasture than those covered by other crop types, especially at the beginning of the campaign. Besides, Figure 16 shows that the canola fields are not invertible for some dates. On Julian day 199, the inversion succeeded over three canola fields (Figure 16c) with an RMSE value around $0.06 \mathrm{~m}^{3} / \mathrm{m}^{3}$. For the corn fields, the accuracy of most of the retrieved results is less than $\pm 0.1 \mathrm{~m}^{3} / \mathrm{m}^{3}$. As for the wheat fields, it should be noted that the in situ measurements are missed on Julian day 185, thus the comparison with the retrieved results cannot be performed (Figure 16b). Figure 16a,c show that over the wheat fields the results are underestimated mainly due to the bias of $\beta$ values (Figure 13), which stems from the partial removal of the volume scattering component (Figure 10).

\subsection{Validation}

In Figure 17, for each crop type, the time series of the mean value of the retrieved soil moisture are presented, along with that of in situ soil moisture measurements:

- $\quad$ For the canola (Figure 17a), soil moisture cannot be inverted for the most part of the phenological period (around $80 \%$ ). Even if after removing the volume scattering contribution the surface scattering component is dominant over the canola fields (Figure 12), the second condition that its $\beta_{\text {data }}$ values should be confined between -1 and 0 is generally not respected. Therefore, the obtained low values of $\beta_{\text {data }}$ (less than -1 ) are considered as non-theoretically correct for soil moisture inversion. These invalid low values of the extracted $\beta_{\text {data }}$ are a consequence of the limitations observed in the modeling of the volume scattering of canola fields. However, although the soil moisture can be retrieved on some days (e.g. around the days of June 23 and July 14) with a RMSE of $0.076 \mathrm{~m}^{3} / \mathrm{m}^{3}$ and a correlation of 0.62 , the low inversion rate (20\%) limits the application of this algorithm to canola crops.

- For the corn (Figure 17b), the temporal evolution of the measured and the retrieved soil moisture agrees well up to Julian day 190 (July 8th). According to the temporal evolution of vegetation characteristics presented in Figure 3, high height (more than $150 \mathrm{~cm}$ ), biomass (more than $3.5 \mathrm{~kg} / \mathrm{m}^{2}$ ), vegetation water content (more than $2.8 \mathrm{~kg} / \mathrm{m}^{2}$ ) and fast changes in corn structure can explain the higher difference observed between the measured and the retrieved soil moisture after Julian day 190.

- For the pasture (Figure 17c), RMSE of $0.098 \mathrm{~m}^{3} / \mathrm{m}^{3}$ is obtained. However, there is no correlation between the temporal variation of the retrieved and the measured soil moisture. A possible reason may be the large $s t d$ values of the measured soil moisture over pasture fields (Figure 16). Besides, compared to the agricultural fields, the pasture characteristics are more heterogeneous.

- For the soybean (Figure 17d), the retrieval is achieved with a correlation of 0.6 and RMSE of $0.078 \mathrm{~m}^{3} / \mathrm{m}^{3}$. The temporal variation of the three scattering mechanisms of soybean (Figure 6) is in agreement with its phenological development (Figure 3), and the simulations and the extracted values of $\beta$ matched (Figure 13). Thus, the three predefined fixed vegetation orientation cases are considered suitable to model the vegetation contribution for soil moisture inversion from the full polarimetric signature of soybean fields.

- For the wheat (Figure 17e), the inversion is only achieved for $70 \%$ of the investigated period, with a correlation of 0.66 and RMSE of $0.12 \mathrm{~m}^{3} / \mathrm{m}^{3}$. Using single polarization ENVISAT ASAR data normalized at $20^{\circ}$, higher retrieval accuracies (RMSE of $5.3 \%$ vol. and $6.4 \%$ vol., for respectively $\mathrm{HH}$ and VV) were obtained by [27] over wheat fields characterized by vegetation water content ranging from $0.08-1.15 \mathrm{~kg} / \mathrm{m}^{2}$. Compared to our dataset, both the lower incidence and the lower vegetation water content are very helpful for improving the retrieval accuracy. 
With RMSE values varying from $0.07-0.12 \mathrm{~m}^{3} / \mathrm{m}^{3}$, Figure 17 shows that the performance of the retrieval algorithm is crop type and phenological stage dependent. The soil moisture is underestimated over most of the crop fields, except for the corn. This result can be explained by the dipole modeling of crop shape [1] and the predefined fixed volume coherency matrices (only three types). Indeed, it is reported in [1] that assuming a dipole particle shape will lead to an underestimation of soil moisture. In [1], the soil moisture retrieval over corn fields is the best with RMSE of $0.08 \mathrm{~m}^{3} / \mathrm{m}^{3}$ during the temporal comparison with ground measurements. For the fields covered by canola and wheat, the RMSEs are around $0.10-0.14 \mathrm{~m}^{3} / \mathrm{m}^{3}$. In this study, by using only the surface scattering mechanism and neglecting the dihedral scattering mechanism which is affected by both the characteristics of vegetation and the underlying soils, the obtained RMSEs are $0.064 \mathrm{~m}^{3} / \mathrm{m}^{3}$ for corn, $0.076 \mathrm{~m}^{3} / \mathrm{m}^{3}$ for canola and $0.12 \mathrm{~m}^{3} / \mathrm{m}^{3}$ for wheat. Nevertheless, in terms of performances, a comparison cannot be made between the soil moisture retrievals conducted in this study and in [1], due to the difference in the experimental conditions including the location of test areas, the crop growth stages and the soil and vegetation characteristics.

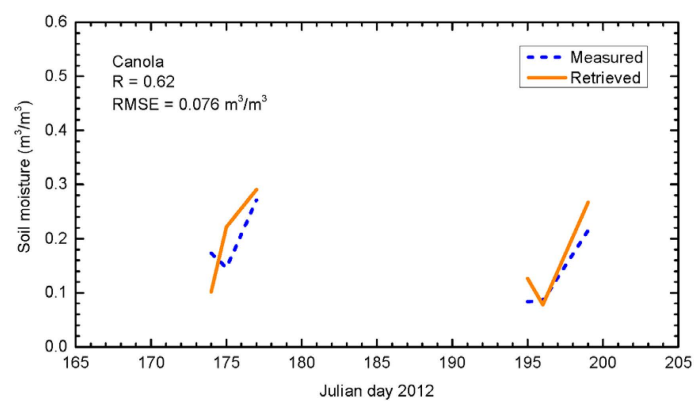

(a)

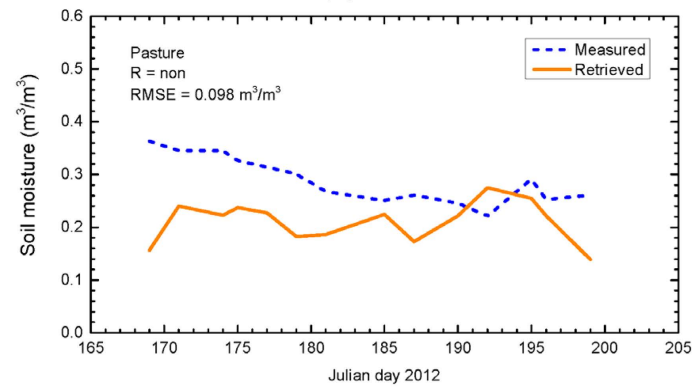

(c)

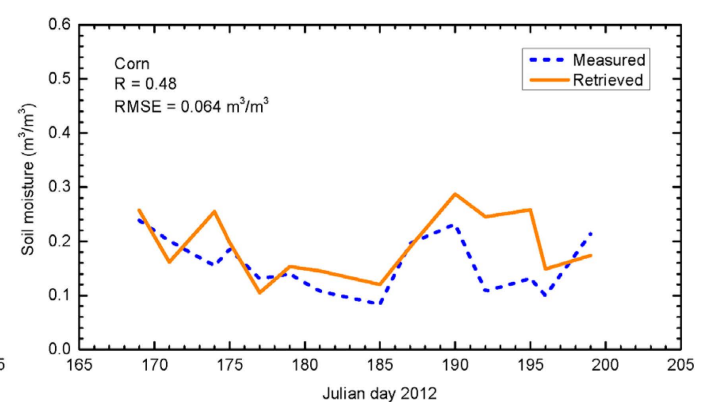

(b)

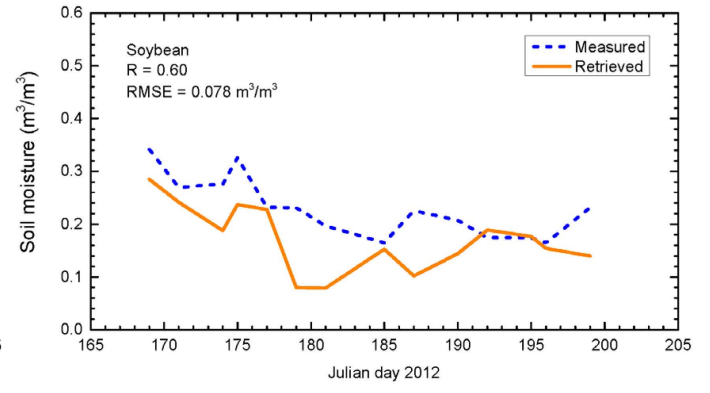

(d)

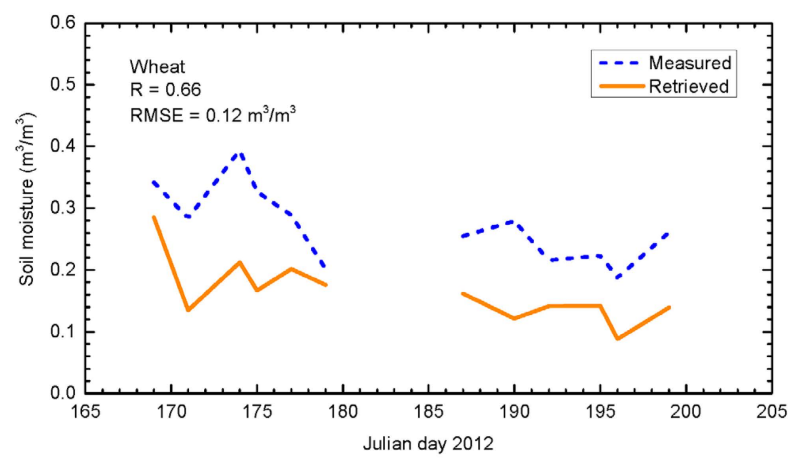

(e)

Figure 17. Comparison between the retrieved and measured soil moisture during the agricultural campaign for (a) Canola; (b) Corn; (c) Pasture; (d) Soybean; (e) Wheat. The retrieved and measured soil moisture are averaged for each crop type, and the discontinuities in the curves correspond to unsuccessful retrieval periods. 


\section{Conclusions}

This study investigates a simplification of the polarimetric decomposition algorithm of [1] for soil moisture retrieval over different agricultural fields of the SMAPVEX12 site by using only the surface scattering component. In comparison to [1], the volume scattering intensity is corrected by the eigen-based algorithm in order to restrict the negative power in the decomposed scattering mechanisms. Furthermore, to our knowledge, it is one of the first studies where a large dataset of multi-temporal SAR airborne measurements acquired over several vegetation covers (canola, corn, pasture, soybean and wheat) is used in order to discuss the potential of an L-band soil moisture decomposition algorithm for fields with different vegetation characteristics and a high dynamic of soil moisture.

Although a simplified soil moisture retrieval procedure is used, the obtained inversion rate of $26 \%-38 \%$ is higher than that of $5 \%-25 \%$ in [1], but still lower than that of $30 \%-49 \%$ in [2] for single acquisition. Difference in agricultural field conditions and in UAVSAR acquisitions could be an explanation. Furthermore, the simplification made by using only the dominant surface scattering component allows the soil moisture estimation, without any ambiguity that could be encountered by integrating the dihedral component in the retrieval process.

The main limitation of this simplification consists of the non-applicability of this simplified algorithm when the dihedral scattering mechanism is dominant. For canola fields, this occurs at the beginning of SMAPVEX12 campaign. At this stage, less than $10 \%$ of the pixels within the canola field are characterized by dominant surface scattering. Nevertheless, with the vegetation growth, the dihedral component decreases. However, the algorithm can retrieve the soil moisture only if the extracted $\beta$ values are physically correct as a result of appropriate removal of the volume scattering component. This second condition allows the inversion from the proposed physically based algorithm only if the field conditions are in agreement with the scattering processes. The discontinuities observed in Figure 17a,e express the violation of this condition.

In addition to the crop phenology, it clearly appears that the performance of the soil moisture retrieval algorithm also depends on the crop types. The algorithms seem to be more suitable for crop types with a structure similar to soybean (short height and low biomass), as the volume scattering contribution can be properly modeled and removed. However, as shown in Figure 1, the investigated fields are distributed along the range. Consequently, the retrieval accuracy is affected by the incidence angle varying from the near range $\left(25^{\circ}\right)$ to the far range $\left(65^{\circ}\right)$. Even if a given field is observed with the same incidence angle from one acquisition date to another, the fields of a given crop type are observed with different incidence angles. These incidence angle variations are not taken into account in the evaluation of the retrieval accuracy, since the main objective of this study is to analyze the potential of polarimetric decomposition for soil moisture retrieval under various vegetation characteristics. Comparing our results with those from a preliminary inversion using the same UAVSAR dataset and two SMAP candidate radar-only algorithms which were applied to a few fields of the SMAPVEX12 campaign [19], the accuracies of the soil moisture retrieval are similar.

Due to the difficulty to account for the real complexity of crop structure during the vegetation growing period, this study also confirms that the modeling of volume scattering contribution is the major challenge for this kind of algorithm. A solution for removing a varying volume scattering is recently proposed and consists of modifying the particle shape and orientation for each resolution cell to individually adapt the vegetation structure [3]. However, such modeling of the general volume scattering may require more parameters to describe the shape, orientation and phenological stage of crop. It might lead to an optimization for volume scattering subtraction instead of direct inversion of soil moisture [3]. Ongoing work is specially focused on improving the vegetation volume scattering component for a better soil moisture retrieval over vegetated agricultural fields.

Acknowledgments: This paper extended our work from IGARSS 2015. The study was funded by the Canadian Space Agency Class Grant and Contribution Program as part of the Canadian plan to spatial missions of soil moisture, and by the National Science and Engineering Research Council of Canada. The authors would like 
to thank the National Aeronautics and Space Administration (NASA) for providing the UAVSAR datasets and the SMAPVEX12 funding agencies in Canada and US (Agriculture and Agri-Food Canada, United States Department of Agriculture, University of Manitoba, University of Guelph, Université de Sherbrooke, University of Southern California, Massachusetts Institute of Technology, Environment Canada, Canadian Space Agency, and National Aeronautics and Space Administration. The authors also thank all the crews of the SMAPVEX12 field campaign for collecting this successful dataset and the anonymous reviewers for improving the paper.

Author Contributions: Hongquan Wang, Ramata Magagi and Kalifa Goita designed the work, realized the idea, analyzed the results, wrote and revised the manuscript. Thomas Jagdhuber commented the methods in detail, provided the suggestions for the results analysis and for the writing of the manuscript. Irena Hajnsek reviewed the manuscript, and provided the suggestions and comments for the results analysis.

Conflicts of Interest: The authors declare no conflict of interest.

\section{References}

1. Hajnsek, I.; Jagdhuber, T.; Schon, H.; Papathanassiou, K.P. Potential of estimating soil moisture under vegetation cover by means of PolSAR. IEEE Trans. Geosci. Remote Sens. 2009, 47, 442-454. [CrossRef]

2. Jagdhuber, T.; Hajnsek, I.; Bronstert, A.; Papathanassiou, K.P. Soil moisture estimation under low vegetation cover using a multi-angular polarimetric decomposition. IEEE Trans. Geosci. Remote Sens. 2013, 51, 2201-2215. [CrossRef]

3. Jagdhuber, T.; Hajnsek, I.; Papathanassiou, K. An iterative generalized hybrid decomposition for soil moisture retrieval under vegetation cover using fully polarimetric SAR. IEEE J. Sel. Top. Appl. Earth Obs. Remote Sens. 2014, 8, 1-12. [CrossRef]

4. Ulaby, F.T.; Moore, R.K.; Fung, A.K. Microwave Remote Sensing: Active and Passive, Vol. II-Radar Remote Sensing and Surface Scattering and Emission Theory; Addison-Wesley Publishing Company, Advanced Book Program/World Science Division: Boston, MA, USA, 1982.

5. Gherboudj, I.; Magagi, R.; Berg, A.A.; Toth, B. Soil moisture retrieval over agricultural fields from multi-polarized and multi-angular RADARSAT-2 SAR data. Remote Sens. Environ. 2011, 115, $33-43$. [CrossRef]

6. Fung, A.K. Microwave Scattering and Emission Models and Their Applications; Artech House Signal Processing Library: Norwood, CO, USA, 1994.

7. Attema, E.P.W.; Ulaby, F.T. Vegetation modeled as a water cloud. Radio Sci. 1978, 13, 357-364. [CrossRef]

8. Allain, S.; Ferro-Famil, L.; Pottier, E. New eigenvalue-based parameters for natural media characterization. In Proceedings of the 2005 IEEE International Geoscience and Remote Sensing Symposium, Seoul, Korea, 25-29 July 2005; pp. 40-43.

9. Allain, S.; Ferro-Famil, L.; Pottier, E. Two novel surface model based inversion algorithms using multi-frequency PolSAR data. In Proceedings of the 2004 IEEE International Geoscience and Remote Sensing Symposium, Anchorage, AK, USA, 2004; pp. 823-826.

10. Freeman, A.; Durden, S.L. A three-component scattering model for polarimetric SAR data. IEEE Trans. Geosci. Remote Sens. 1998, 36, 963-973. [CrossRef]

11. Yamaguchi, Y.; Moriyama, T.; Ishido, M.; Yamada, H. Four-component scattering model for polarimetric SAR image decomposition. IEEE Trans. Geosci. Remote Sens. 2005, 43, 1699-1706. [CrossRef]

12. Cloude, S.R.; Pottier, E. A review of target decomposition theorems in radar polarimetry. IEEE Trans. Geosci. Remote Sens. 1996, 34, 498-518. [CrossRef]

13. Baghdadi, N.; Cresson, R.; Pottier, E.; Aubert, M.; Zribi, M.; Jacome, A.; Benabdallah, S. A potential use for the C-band polarimetric SAR parameters to characterize the soil surface over bare agriculture fields. IEEE Trans. Geosci. Remote Sens. 2012, 50, 3844-3858. [CrossRef]

14. Baghdadi, N.; Dubois-Fernandez, P.; Dupuis, X.; Zribi, M. Sensitivity of main polarimetric parameters of multifrequency polarimetric SAR data to soil moisture and surface roughness over bare agricultural soils. IEEE Geosci. Remote Sens. Lett. 2013, 10, 731-735. [CrossRef]

15. Baghdadi, N.; Zribi, M.; Loumagne, C.; Ansart, P.; Anguela, T.P. Analysis of TerraSAR-X data and their sensitivity to soil surface parameters over bare agricultural fields. Remote Sens. Environ. 2008, 112, 4370-4379. [CrossRef]

16. Bindlish, R.; Barros, A.P. Parameterization of vegetation backscatter in radar-based, soil moisture estimation. Remote Sens. Environ. 2001, 76, 130-137. [CrossRef] 
17. Mattia, F.; Le Toan, T.; Souyrb, J.; De Carolis, G.; Floury, N.; Posa, F.; Pasquariello, G. The effect of surface roughness on multifrequency polarimetric SAR data. IEEE Trans. Geosci. Remote Sens. 1997, 35, 954-966. [CrossRef]

18. SMAP Validation Experiment 2012. Available online: https://smapvex12.espaceweb.usherbrooke.ca/ (accessed on 4 February 2016).

19. McNairn, H.; Jackson, T.J.; Wiseman, G.; Belair, S.; Berg, A.; Bullock, P.; Colliander, A.; Cosh, M.H.; Kim, S.-B.; Magagi, R.; et al. The Soil Moisture Active Passive Validation Experiment 2012 (SMAPVEX12): Prelaunch calibration and validation of the SMAP soil moisture algorithms. IEEE Trans. Geosci. Remote Sens. 2015, 53, 2784-2801. [CrossRef]

20. Lee, J.S.; Pottier, E. Polarimetric Radar Imaging from Basics to Applications; CRC Press: Boca Raton, FL, USA, 2009.

21. Cosh, M. SMAPVEX12 Vegetation Water Content Map; NASA National Snow and Ice Data Center Distributed Active Archive Center: Boulder, MT, USA, 2014.

22. Hajnsek, I.; Pottier, E.; Cloude, S.R. Inversion of surface parameters from polarimetric SAR. IEEE Trans. Geosci. Remote Sens. 2003, 41, 727-744. [CrossRef]

23. Van Zyl, J.J.; Arii, M.; Kim, Y. Model-based decomposition of polarimetric SAR covariance matrices constrained for nonnegative eigenvalues. IEEE Trans. Geosci. Remote Sens. 2011, 49, 3452-3459. [CrossRef]

24. Topp, G.C. Electromagnetic determination of soil water content: Measurements in coaxial transmission lines. Water Resour. Res. 1980, 16, 574-582. [CrossRef]

25. Cloude, S.R.; Pottier, E. An entropy based classification scheme for land applications of polarimetric SAR. IEEE Trans. Geosci. Remote Sens. 1997, 35, 68-78. [CrossRef]

26. Willmott, C.J. Some comments on the evaluation of model performance. Bull. Am. Meteorol. Soc. 1982, 63, 1309-1313. [CrossRef]

27. Zribi, M.; Chahbi, A.; Shabou, M.; Lili-Chabaane, Z.; Duchemin, B.; Baghdadi, N.; Amri, R.; Chehbouni, A. Soil surface moisture estimation over a semi-arid region using ENVISAT ASAR radar data for soil evaporation evaluation. Hydrol. Earth Syst. Sci. 2011, 15, 345-358. [CrossRef]

(C) 2016 by the authors; licensee MDPI, Basel, Switzerland. This article is an open access article distributed under the terms and conditions of the Creative Commons by Attribution (CC-BY) license (http://creativecommons.org/licenses/by/4.0/). 